Article

\title{
Study of Unwanted Emissions in the CENELEC-A Band Generated by Distributed Energy Resources and Their Influence over Narrow Band Power Line Communications
}

\author{
Noelia Uribe-Pérez ${ }^{1, *}$, Itziar Angulo ${ }^{2}$, Luis Hernández-Callejo ${ }^{3}$, Txetxu Arzuaga ${ }^{4}$, \\ David de la Vega ${ }^{2}$ and Amaia Arrinda ${ }^{2}$ \\ 1 Centre for the Development of Renewable Energy Sources-Research Centre for Energy, Environment and \\ Technology (CEDER-CIEMAT), 42290 Lubia, Spain \\ 2 Department of Communications Engineering, ETSI Bilbao, University of the Basque Country (UPV/EHU), \\ 48013 Bilbao, Spain; itziar.angulo@ehu.es (I.A.); david.delavega@ehu.es (D.d.l.V.); \\ amaia.arrinda@ehu.es (A.A.) \\ 3 Department of Agricultural Engineering and Forestry, University of Valladolid (UVA), 42004 Soria, Spain; \\ luis.hernandez.callejo@uva.es \\ 4 ZIV LV Products, CG Automation BU, 48170 Zamudio, Spain; txetxu.arzuaga@cgglobal.com \\ * Correspondence: noelia.uribe@ciemat.es; Tel.: +34-97-5281-013 (ext. 105)
}

Academic Editor: Josep M. Guerrero

Received: 27 September 2016; Accepted: 18 November 2016; Published: 30 November 2016

\begin{abstract}
Distributed Energy Resources might have a severe influence on Power Line Communications, as they can generate interfering signals and high frequency emissions or supraharmonics that may cause loss of metering and control data. In this paper, the influence of various energy resources on Narrowband Power Line Communications is described and analyzed through several test measurements performed in a real microgrid. Accordingly, the paper describes the effects on smart metering communications through the Medium Access Control (MAC) layer analysis. Results show that the switching frequency of inverters and the presence of battery chargers are remarkable sources of disturbance in low voltage distribution networks. In this sense, the results presented can contribute to efforts towards standardization and normative of emissions at higher frequencies higher, such as CENELEC EN 50160 and IEC/TS 62749.
\end{abstract}

Keywords: Distributed Energy Resources; meter reading; microgrids; Narrow-Band Power Line Communications; noise

\section{Introduction}

With the increasing development of the Distributed Generation (DG) and Distributed Storage (DS), the role of Distributed Energy Resources (DERs) is taking more relevance. DERs are considered key agents in the shift towards upcoming electricity paradigms such as Smart Grids (SGs) and microgrids.

Additionally, Power Line Communications (PLC) is one of the most spread technologies for data transmission in smart metering systems [1]. In fact, most installations in Europe and China use this technology due its lower cost compared to alternative wireless solutions and faster deployment since the communication channel is already installed [2].

Despite the very promising features of PLC for the SG, they can be highly affected if strong disturbances are present in the transmission channel [3]. These disturbances must be characterized in order to both identify potential impact situations and to develop strategies that overcome the communications impairments. Power inverters, due to the high amplitude spurious signals within a wide frequency band that are generated in the switching process, are one of the Low Voltage (LV) 
grid elements that must be considered [4]. Also battery chargers, pumps and turbines' influence must be addressed since their electrical nature might affect PLC [5].

In this paper the influence of noise and spurious signals within the 2 to $150 \mathrm{kHz}$ frequency range generated by DERs on the performance of Narrowband Power Line Communications NB-PLC in a microgrid environment is tackled. For this purpose, the potential effects of the noise generated by several energy sources on the quality of NB-PLC are analysed through a measurement campaign performed in a real microgrid with an integrated smart metering system based on PoweRline Intelligent Metering Evolution (PRIME). The main spurious and noise sources are identified in the obtained spectra and their influence in the NB PLC subnetwork topology is addressed. The work also includes an analysis of the MAC frames involved in the subnetwork set up and data transmission. Finally, the document presents the main conclusions and contributions of the work.

The document is organized as follows: Section 2 describes the actual concerns regarding supraharmonics as well as their influence over PLC, highlighting the importance of addressing them within the context of microgrids. Section 3 describes the main features of PRIME. Section 4 presents the measurement setup and methodology employed and describes the tests carried out for this work. Section 5 includes the results and analysis obtained from the aforementioned measurements for each of the considered DERs operating alone while Section 6 includes the results and analysis from the measurements performed for each of the devices operating in a real microgrid, with the rest of surrounding DERs operating as well. Finally, Section 7 discusses the obtained results and contributions and Section 8 summarizes the main conclusions from this work.

\section{Disturbances Introduced by Distributed Energy Resources in Power Line Communications}

PLC technology uses the electrical grid for data transmission. NB-PLC is typically used for smart metering, control and home-area services and it operates in the frequency range from 3 to $500 \mathrm{kHz}$ [6]. NB-PLC is regulated by CENELEC standard in Europe, and specifically CENELEC-A band (3-95 kHz) has been planned for utilities. Examples of NB-PLC technologies are ITU-T G.hnem, IEEE 1901.2, PRIME and G3.

Non-intended or spurious emissions in the frequency band from several $\mathrm{kHz}$ to hundreds of $\mathrm{kHz}$, also referred to as "supraharmonics", are attracting the attention of the scientific community. As highlighted in [5], different types of electrical equipment are showing high emissions in the frequency range below $150 \mathrm{kHz}$ and are to be considered as potential for electromagnetic interferences to other electrical equipment, including PLC systems. Within supraharmonics range, emissions driven by a certain device are known as "primary emission" while the emission generated by other devices are considered "secondary emission" [7]. The importance of these high-frequency emissions is reflected in the creation of several working groups in the main international associations and standardization committees, such as CIGRE/CIRED joined group C4.24, IEEE EMC Society TC 7 and CENELEC SC205A, among others [8].

On one hand, the interest in distortion in the considered frequency range is due to an increasing number of sources of emission, including energy-efficient lighting and generation (such as DERs) and some other electrical equipment within the LV sector of the electricity distribution network [9-12]. In fact, the switching frequency of the converters present in much grid-connected equipment is commonly within the $2-150 \mathrm{kHz}$ range [4]. This situation directly affects to upcoming electricity paradigms, such as SGs and microgrids, which will encounter more problems in the $2-150 \mathrm{kHz}$ range due to the increasing number of renewable energy resources, and demand for energy efficiency; increasing capacitive behavior of the loads and an unavoidable need for communications. This in turn translates into more switching power converters, increasing higher frequency current due to low impedance of the loads and increasing use of communication technologies, respectively [13].

Some interesting works about supraharmonics can be found in the literature. While [14] presents a study of the waveform distortion in the LV network and includes some field measurements for indoor lighting devices, $[15,16]$ assess the emission of domestic installations and LED lamps up to $150 \mathrm{kHz}$. 
Regarding DERs, the disturbances generated by Photovoltaic (PV) inverters in higher frequencies have been tackled in literature $[17,18]$ as well as simulated [19] and field-measured [20]. Some researches regarding wind turbine harmonic emissions in the higher frequency can be also found in $[21,22]$ and the emission of high frequency harmonics caused by electrical vehicle charging is addressed in [23]. Additionally, [24] provides a review of standards and technical reports as well as some laboratory measurements regarding emissions and immunity within the smart metering context in the $2-150 \mathrm{kHz}$ range. Finally, some other publications address detected problems of high frequency harmonics in public LV distribution grids, such as [25-27].

On the other hand, another reason of concern is the potential influence and consequences of high frequency emissions over PLC systems [28-31]. In fact, the noise model in PLC is more complex than in other traditional communication systems, since it consists of coloured broadband noise, narrowband interference and different types of impulsive noise [32]. A general overview of the performance of PLC in electrical networks can be seen in $[33,34]$. While a wide amount of studies dealing with the influence of emissions in PLC focus on domestic devices [35,36], also analyses of PLC disturbances in electrical vehicles can be found in literature [37]. Finally, [38] includes several simulations of the suitability of PLC for smart metering under different noise conditions.

Regarding DERs, their negative influence in PLC may be higher, due to distributed location of these devices, in many cases close to the homes or even within the home of the prosumers, and therefore, close to the smart meters. Nevertheless, it has been barely addressed and more empirical tests are needed; as an example, studies of the influence of some other DERs such as hydropower systems or battery charges in PLC have not been found in the literature. This effect becomes crucial in microgrids, where DERs are located near the PLC equipment, and moreover, data provided by smart meters is important for the proper management of the power balance between generation, storage and consumption. To that end, this work focuses on the influence of DERs over NB-PLC in a real microgrid, with an emphasis on the empirical approach to this topic. In this sense, the results presented here are a valuable contribution regarding the actual efforts towards standardization and normative of emissions at frequencies higher than harmonics, such as CENELEC EN 50160 and IEC/TS 62749 [8].

\section{PoweRline Intelligent Metering Evolution}

The NB-PLC technology deployed in the microgrid that is analysed in this work is PRIME v1.3.6, which uses the frequency band from 41.992 to $88.867 \mathrm{kHz}$. Its key features are described below. PRIME employs several techniques to overcome channel disturbances. In the physical layer it uses Orthogonal Frequency-Division Multiplexing (OFDM) modulation and coding techniques, while the MAC layer is based on the automatic reconfiguration of the network.

\subsection{Physical Layer}

OFDM is known by its good performance against frequency selective interferences. When it is combined with Forward Error Correction (FEC) coding, data transmission can face adverse channel impairments and noise scenarios. The FEC mechanism consists of a convolutional encoder together with a block interleaver. Additionally, other techniques such as limiting the amplitude of the incoming time samples or enhancing the correction capabilities of a Viterbi decoder by interleaving bits among several OFDM symbols instead of interleaving over one symbol increase the performance of PRIME under impulsive noise environments [39].

\subsection{Medium Access Control Layer}

PRIME devices are disposed in a tree structure where two types of nodes are possible: Base Node (BN), which acts as a master node of the subnetwork and is in charge of all the resources and connections; and Service Node (SN), which keeps connectivity to the subnetwork and switches the data of other nodes to propagate connectivity, if required. While BNs are embedded in the Data 
Concentrators (DCs), the SNs are included in the Smart Meters (SMs). SNs can have three functional states [40], as Figure 1 shows:

- Disconnected: it is the initial state, in which SNs are not able to communicate or switch data.

- Terminal: where SNs are able to establish connections and transmit data, but not to switch the data of other nodes.

- Switch: in this state SNs are able to forward data to and from other nodes within the subnetwork. Additionally, they keep all terminal state functions.

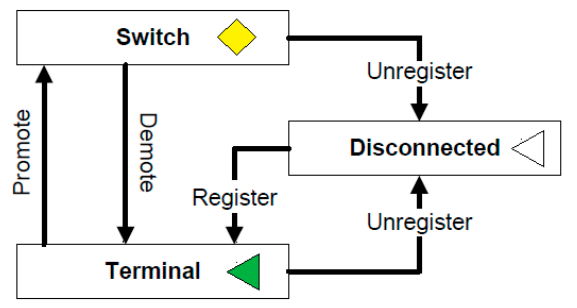

Figure 1. Different states of the SNs in PRIME. The SN representation varies according its role: yellow diamond for switch, green triangle for terminal and empty triangle for disconnected.

PRIME can tackle noise by promoting nodes to switch state. If the communication capabilities of a $\mathrm{SN}$ are affected by noise disturbances, the $\mathrm{BN}$ can decide to promote a neighbor $\mathrm{SN}$ from terminal to switch state in order to ensure the communication between the affected $\mathrm{SN}$ and the BN.

The evolution of the topology of a PRIME subnetwork can be obtained in the form of $\log$ files, which also provide information regarding the coverage of each SN. The coverage indicates the probability $P$ of a successful communication between the $\mathrm{BN}$ and a $\mathrm{SN}$ within the same subnetwork. The BN sets these values, which are quantified from 1 to 6 with the criteria specified in Table 1 . It can be considered as a joint evaluation of the performance of the communications uplink and downlink.

Table 1. Probability $P$ of a successful communication between the $\mathrm{BN}$ and a $\mathrm{SN}$ within the same subnetwork and its corresponding coverage value.

\begin{tabular}{cc}
\hline Coverage Value & Probability $\boldsymbol{P}$ \\
\hline 1 & $0<P<0.5$ \\
2 & $0.5<P<0.75$ \\
3 & $0.75<P<0.875$ \\
4 & $0.875<P<0.9375$ \\
5 & $0.9375<P<0.96875$ \\
6 & $0.96875<P<1$ \\
\hline
\end{tabular}

\section{Measurement Setup and Methodology}

The tests were carried out at CEDER-CIEMAT facilities, a national institution for the research, growth and promotion of renewable energies, where a real microgrid has been installed to be managed and monitored [41]. The microgrid has a smart metering system installed, which is based on PRIME standard and currently consists of 53 single-phase and three-phase SMs, in their turn SNs, along with 7 BNs located in each of the DCs installed in the power transformers of the microgrid. Each BN and their registered SMs under the same power transformer form a PRIME subnetwork automatically. Therefore, each subnetwork is independent of the rest of existing subnetworks. Since each BN is located at one transformation center of the microgrid, the analysis of a PRIME subnetwork entails focusing on a unique transformation center.

The measurements included in this work were performed in a transformation center of the microgrid that includes a wide deployment of DERs and controlled loads. The selected subnetwork consists of the devices downstream a transformation center with two power transformers (see Figure 2). 
Downstream, two different branches are considered: on one side, the hydro system branch consisting of the turbine, the pump and the three-phased PV system and on the other, the three single-phased PV systems and the battery charger. Two different DCs were installed, one for each power transformer, in a master-slave configuration, where one acts as the controller of the PRIME subnetwork (BN) and storages metering data from all the nodes within its subnetwork, and the other forwards the data from the SNs located in its electrical branch to the master DC via User Datagram Protocol UDP over PRIME. This subnetwork is composed of 10 SMs and 2 DCs.

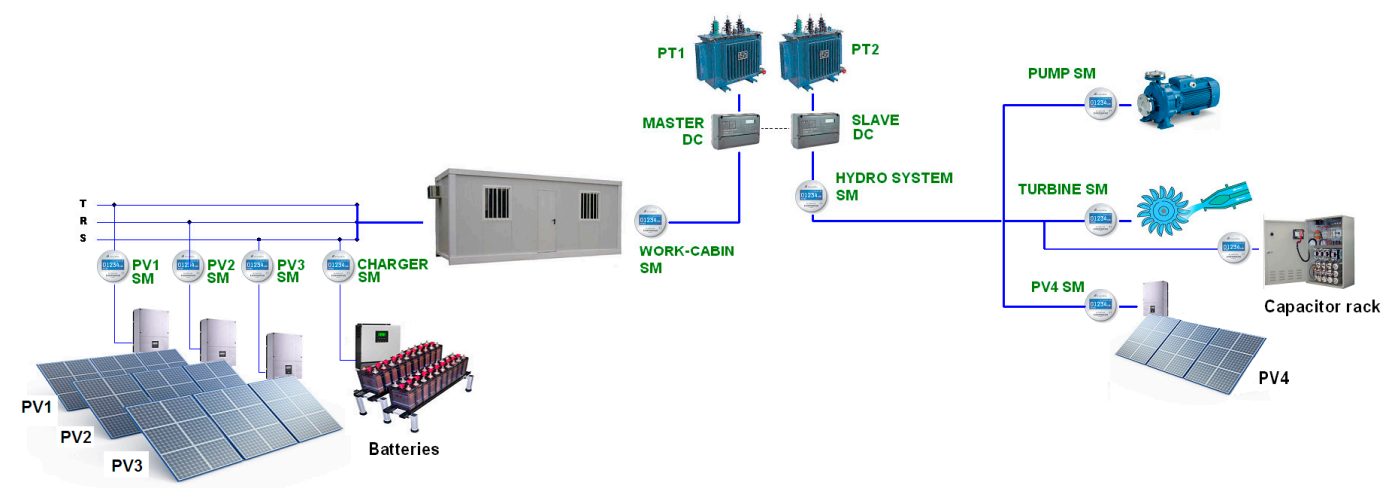

Figure 2. Simplified scheme of the measurement area. The transformation centre counts with two power transformers, located close to each other in the same transformation center, therefore leading to two electrical branches, where different DG and DS resources can be identified. Regarding electrical distances, while the SMs of the work cabin, PV1, PV2, PV3 and battery charger are approximately $13 \mathrm{~m}$. away from the DC, the SMs of the hydro branch (except the hydro system SM, which is located $5 \mathrm{~m}$, away from the DC) are approximately $1.5 \mathrm{~km}$ away from the DC.

The devices considered for this work and their main features, such as operating power and switching frequency for inverters, are outlined in Table 2. Also the different configurations considered for each device are included.

Table 2. List of considered devices, main features and measurement configurations.

\begin{tabular}{ccc}
\hline Type of DER & Features & Configurations \\
\hline Hydropower turbine & $60 \mathrm{~kW}$, three-phased & Off/On/Start/Steady \\
Hydropower pump & $18 \mathrm{~kW}$, three-phased & Off/Start/Steady \\
PV1 inverter & $5 \mathrm{~kW}$, single-phased, @ $16 \mathrm{kHz}$ & On/Start/Steady \\
PV2 inverter & $5 \mathrm{~kW}$, single-phased, @ $16 \mathrm{kHz}$ & On/Start/Steady \\
PV3 inverter & $5 \mathrm{~kW}$, single-phased, @ $16 \mathrm{kHz}$ & On/Start/Steady \\
PV4 inverter & $15 \mathrm{~kW}$, three-phased, @ $16 \mathrm{kHz}$ & On/Start/Steady \\
Battery Charger & $8 \mathrm{~kW}$, single-phased & Off/Stand-by/On \\
\hline
\end{tabular}

The aim of the measurement tests is to empirically analyze the influence of the electric noise generated by DERs in PRIME. The analysis is done in two areas: spectral characterization of the noisy emissions and impact of the disturbances on the subnetwork topology:

- The spectral analysis is addressed by averaging fifteen measurements performed per each particular scenario. Only measurements not containing PRIME frames were considered in the averaging process.

- The potential impact on the subnetwork topology is evaluated by analyzing the evolution of the different possible roles of the nodes and its relation with the features of each scenario. Additionally, the variations in coverage level due to disturbances are addressed.

The experimental setup used in the measurements can be seen in Figure 3, which is composed of the following equipment: 
- TABT-2 capacitive coupler, which allows high-frequency measurements in LV networks and filters out frequencies below $10 \mathrm{kHz}$. This cut off frequency allows the most common switching frequencies of inverters.

- Tektronix TPS-2024 oscilloscope, which provides the spectrum of the transmission channel. The sampling rate is fixed at $1 \mathrm{MS} / \mathrm{s}$, with 8 bits/sample. A Hanning window is applied and a 2048 FFT is internally used to assess the spectrum of the recorded signals.

- Communication sniffer, called PRIME Base Node (PBN), which provides information about MAC packets traffic.

- BN of the PRIME subnetwork, which provides information about network topology evolution and MAC packets traffic, among others. Both the sniffer and the BN are accessed through specific software via Ethernet.

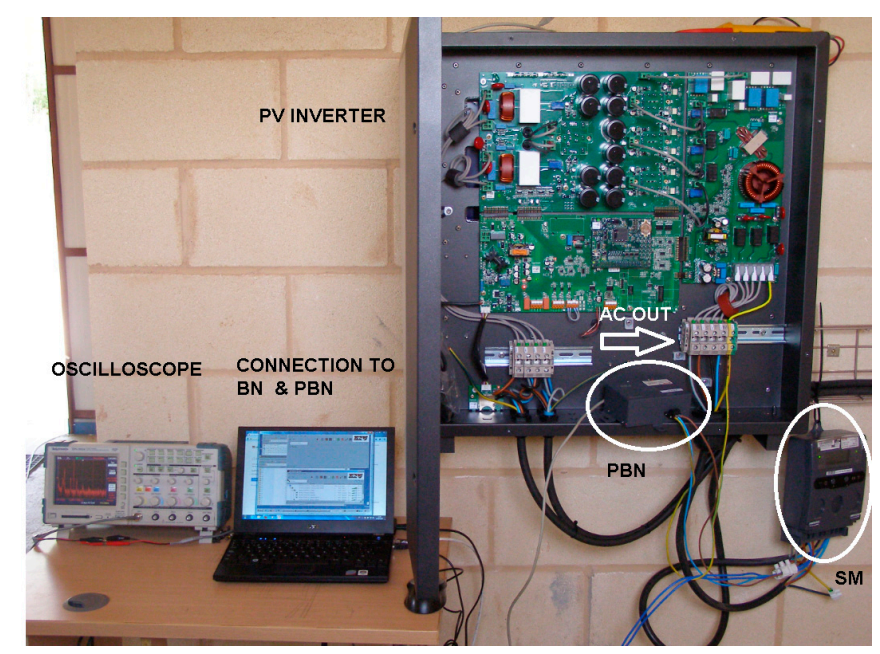

Figure 3. Experimental setup used in the measurements.

For the analysis of the influence of noise over PRIME, two different approaches have been considered. Firstly, measurements have been performed for each of the devices separately and the obtained results have been analyzed (Section 5). Secondly, the measurements have been repeated for each device performing in a real microgrid operation with the rest of surrounding DERs working as well (Section 6). This twofold approach helps to better understand the effects of noise in a real scenario and also shows how PRIME behaves and adapts to noisy environments.

\section{Spectral Disturbances Introduced by Distributed Energy Resources in Narrow-Band Power Line Communications}

This section compiles a set of measurements for different DER devices located at CIEMAT-CEDER microgrid with the aim of measuring their emissions and analysing their influence in NB-PLC. The tests were carried out connecting the capacitive coupler to the AC input of the associated SM of each device with the surrounding emitting devices disconnected. The plots show the frequency range under analysis (41.992 to $88.867 \mathrm{kHz}$ ) adding side margins of $30 \mathrm{kHz}$, aiming at facilitating the understanding of unwanted emissions based on supraharmonics. The lower edge $(10 \mathrm{kHz})$ is set by the inner filter of the coupler used for the measurements. Additionally, as a reference, the measurements include PRIME signals captured in each specific scenario, when possible, in order to provide a power level reference to evaluate the significance of unwanted emissions. Therefore, the PRIME signals included in this paper are different among them since they depend on the network configuration. 


\subsection{Hydropower Turbine}

The hydropower generator located at the facilities of CEDER-CIEMAT is a $60 \mathrm{~kW}$ three-phased Pelton turbine. Once the turbine switches on, it takes approximately 13 seconds to couple to mains and this process is instantaneous. Therefore, three different stages can be differentiated: on, start (when couples to mains) and steady. Additionally, off stage was also recorded. Figure 4 shows the recorded spectra for the different stages of the turbine, operating at $35 \mathrm{~kW}$ for on state. The spectrum of the coloured noise is mainly formed by a set of supraharmonics of decreasing amplitude whose main injection is at $13 \mathrm{kHz}$. The power levels are around $4 \mathrm{~dB}$ above the noise floor at frequencies below $57 \mathrm{kHz}$, and from then on no significant emission from the hydropower turbine is observed. The start operation increases the power levels of lower frequencies while the power levels of the frequencies higher than $41 \mathrm{kHz}$ remain similar to steady operation. In any case, the power level of the recorded PRIME signal is higher than the emissions of the turbine in the entire PRIME band, even considering that the recorded PRIME signal is highly degraded by the transmission channel. During all the tests, the SN of the turbine was connected to the PRIME subnetwork and its coverage remained stable (level values between 4 and 5). Additionally, Figure 5 shows the spectrum recorded for different operating powers of the turbine, where it can be seen that there are not remarkable differences among the power levels of the emissions for different turbine output values.

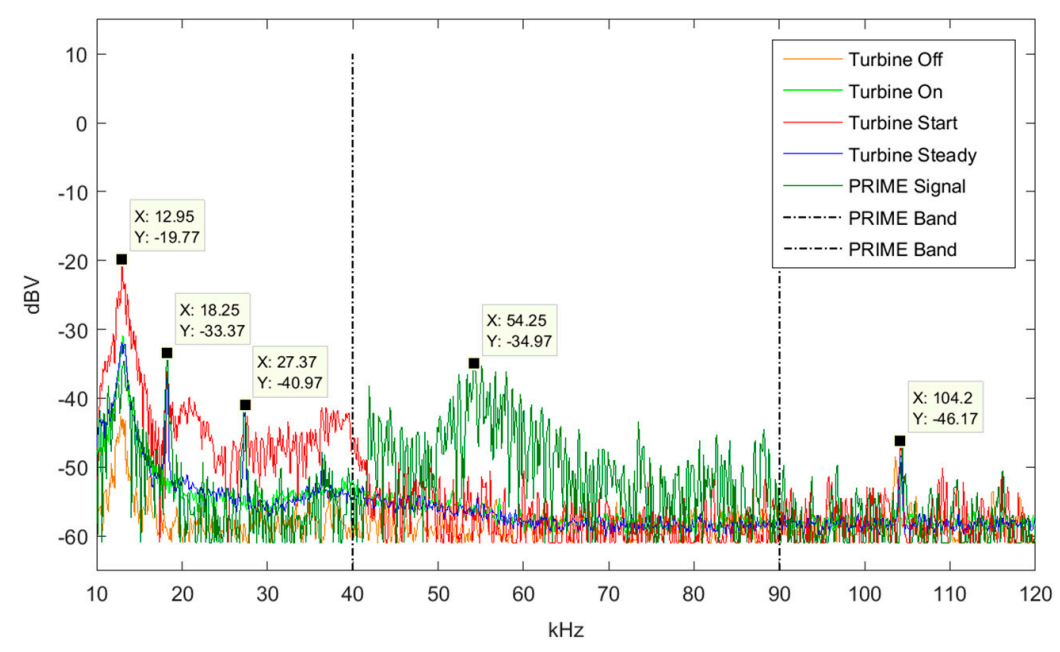

Figure 4. Spectrum recorded at the turbine SM with the rest of devices disconnected.

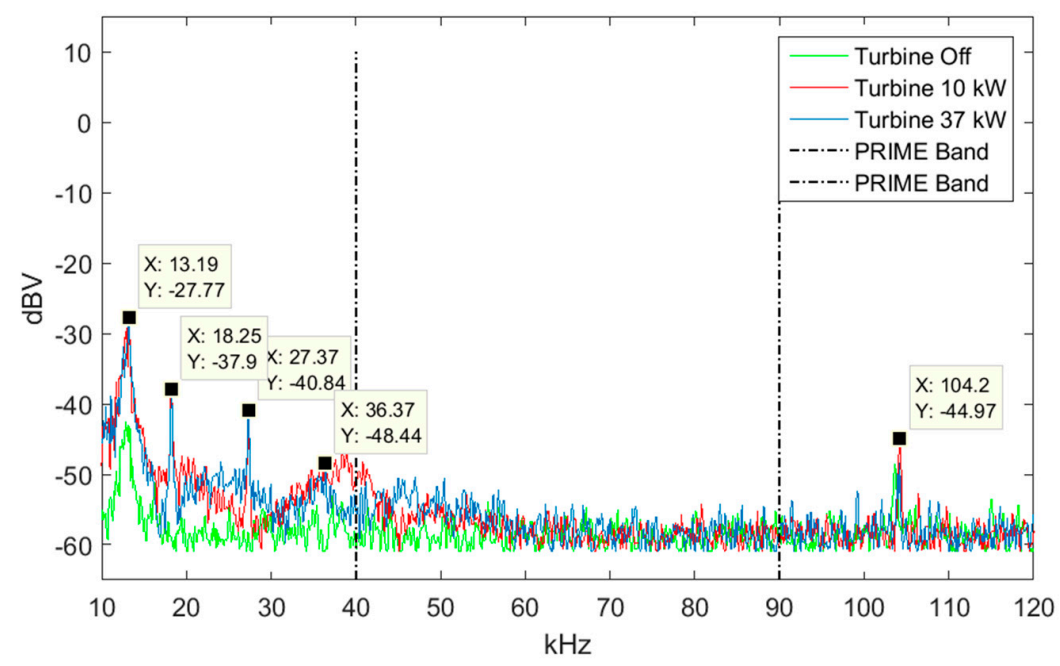

Figure 5. Spectrum recorded at the turbine SM in steady operation for different values of power. 


\subsection{Hydropower Pump}

The hydropower pump is a three-phased machine of $18 \mathrm{~kW}$. Emissions from the pump were recorded for start (the process of coupling to mains, which is immediate) and steady operations. The recorded spectra for the start state (see Figure 6) show a coloured noise whose power level is above noise floor. Power levels of noise are constant during steady operation and slightly increase for start operation inside PRIME band. The highest emissions are observed when the pump couples to mains but the maximum values of the emissions are located out of PRIME band. Within this band, the power levels of the noise are between 5 and $20 \mathrm{~dB}$ below the power level of the recorded PRIME signal. Regarding the influence in communications, the SM of the pump was connected during all the performed tests. Additionally, its coverage remained stable (level 4).

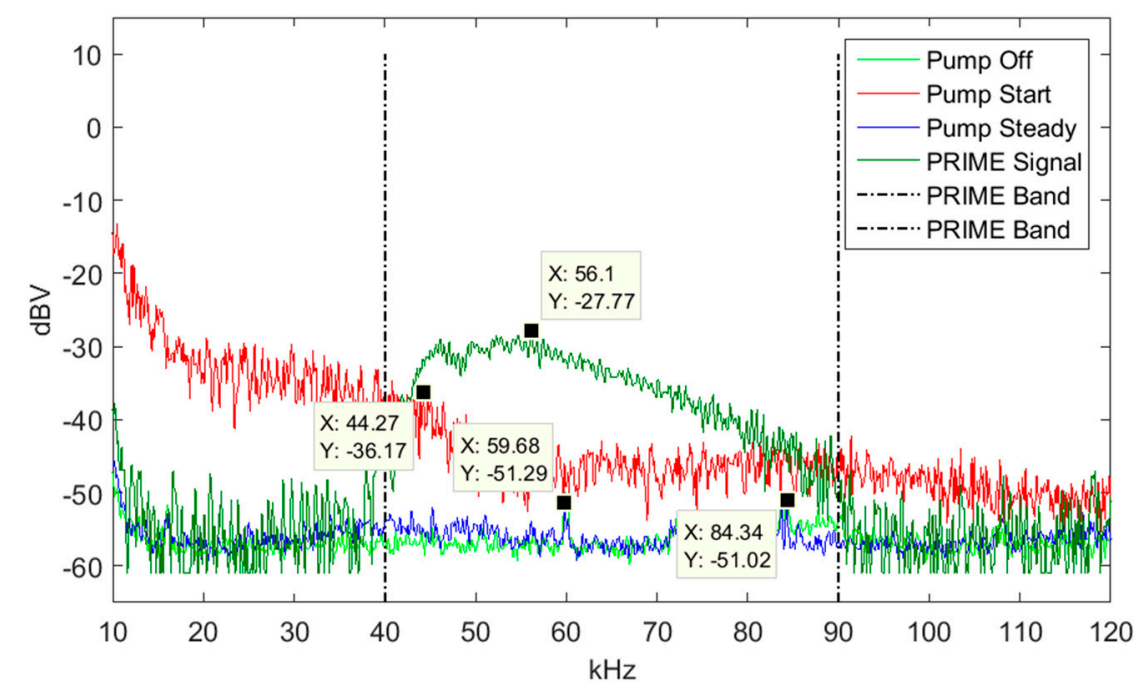

Figure 6. Spectrum recorded at the pump SM with the rest of devices disconnected.

\subsection{Three-Phased PV4 Inverter}

In the same branch where the hydropower system is located, there is a three-phased PV4 inverter of $15 \mathrm{~kW}$ with a switching frequency of $16 \mathrm{kHz}$. Three different states of the inverter are considered: on (the inverter is switched on but not coupled to mains), start (the moment in which the inverter couples to mains) and steady (the inverter in ordinary operation). Figure 7 shows the recorded spectrum at the PV4 SM input when the pump and the hydropower turbine are disconnected. Additionally, the figure includes two recorded PRIME signals. As it can be seen, for start and steady states, there is a primary injection at $16 \mathrm{kHz}$ (equal to the switching frequency of the inverter) whose power level is approximately $35 \mathrm{~dB}$ above the noise floor during the steady phase and $37.3 \mathrm{~dB}$ for the start phase. The power levels of the harmonics of this component located at $32 \mathrm{kHz}, 48 \mathrm{kHz}$ and $64 \mathrm{kHz}$ linearly decrease. In all cases, the power levels of the supraharmonics for start operation are slightly above the obtained ones for the steady operation with a maximum difference of $5.82 \mathrm{~dB}$ at $32 \mathrm{kHz}$. Only two of the harmonics are within PRIME band $(48 \mathrm{kHz}$ and $64 \mathrm{kHz})$ and their power levels are below the PRIME signals (or equal in the case of the "weakest" recorded signal). Regarding the influence in the associated $\mathrm{SN}$, its coverage fluctuated between levels 3 and 5 during normal operation of the inverter (stable) but it remained connected during all the tests. 


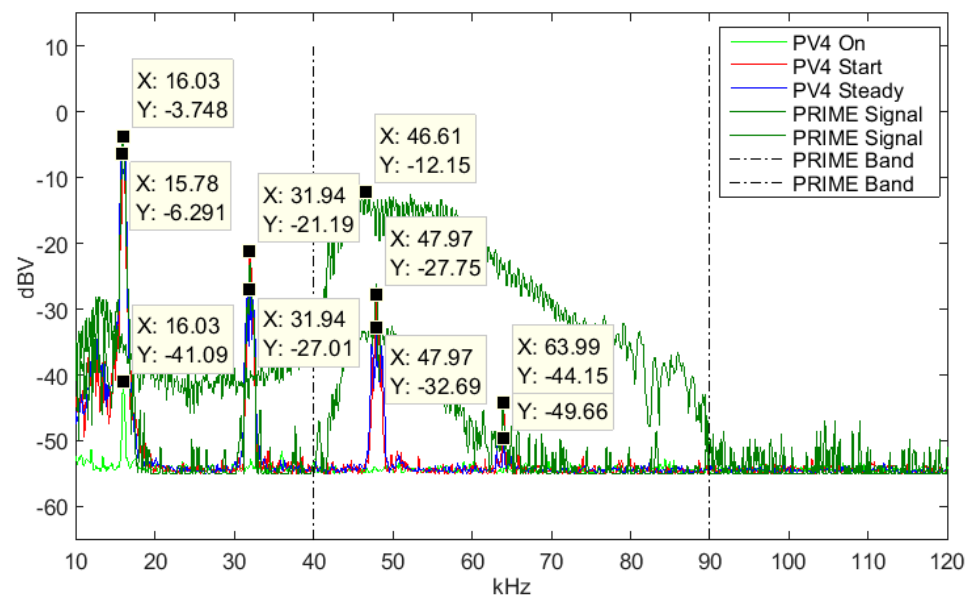

Figure 7. Spectrum recorded at the three-phased PV4 SM with the rest of devices disconnected.

\subsection{Battery Charger}

The battery charger is located on the other branch of the transformation centre along with the three single-phased PV systems. The battery charger is single-phased and has a power of $8 \mathrm{~kW}$. Three different states of the charger have been recorded: off, stand-by and charging (on) operation. The off state is the electrical disconnection of the charger, the stand-by state means that the charger is connected but prior to the conversion stage, and in the on state the charger starts the charging process. The spectra is characterised by coloured noise whose emissions at stand-by are mainly composed by an injection at $12 \mathrm{kHz}$, which is out of PRIME band. The coverage level of the associated SN remained stable (values 5-6) during on and stand-by operations. However, emissions during charging state are composed by a set of supraharmonics of decreasing amplitude whose main injection is at $24 \mathrm{kHz}$ (the switching frequency of the inverter stage of the battery charger), with a power level of almost $57 \mathrm{~dB}$ above noise floor (see Figure 8). The 2nd and 3rd harmonics of the $24 \mathrm{kHz}$ component are within PRIME band. In the case of this specific battery charger, the emissions highly affect PRIME communications, since the associated $\mathrm{SN}$ of the charger and the $\mathrm{BN}$ are not able to communicate and therefore, the $\mathrm{SN}$ is disconnected from the subnetwork. Additionally, Figure 8 includes two PRIME signals recorded during stand-by operation. Observing the signals, it becomes apparent that the strongest signal may correspond to a PRIME signal transmitted by the $\mathrm{SN}$, whereas the weakest signal may correspond to a signal received from the $\mathrm{BN}$, which has been attenuated by the transmission channel.

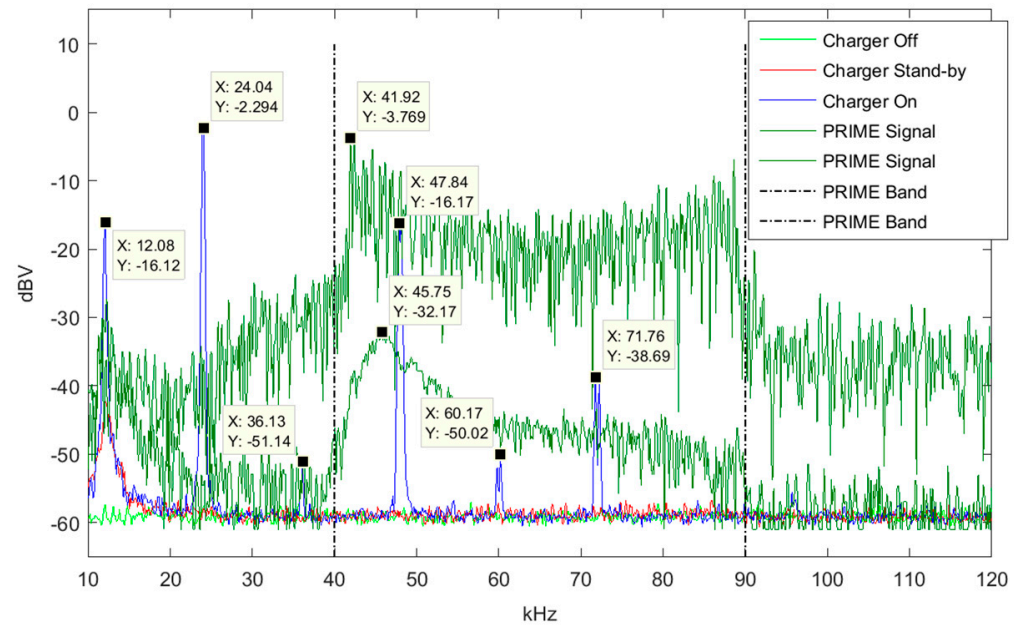

Figure 8. Spectrum recorded at the battery charger SM with the rest of devices disconnected. 


\subsection{Single-Phased Photovoltaic Inverters}

In the same branch where the battery charger is located, there are three single-phased PV inverters. All of them have a power of $5 \mathrm{~kW}$ and a switching frequency of $16 \mathrm{kHz}$. Measurements were performed for three states: inverter on but prior to coupling to mains, start (process of coupling to mains) and steady (inverter working and coupled to mains).

\subsubsection{PV1}

The analysis of the spectrum shows a similar coloured noise pattern for on and start states with a primary injection at $16 \mathrm{kHz}$, which coincides with the switching frequency of the inverter, and almost $65 \mathrm{~dB}$ above the noise floor (see Figure 9). Only the 3rd harmonic of the main component is within PRIME band and its power level is approximately $12 \mathrm{~dB}$ below the power level of the recorded PRIME signal at the same frequency. Additionally, the SN of PV1 remained connected and its coverage stable, with values between 5 and 6 .

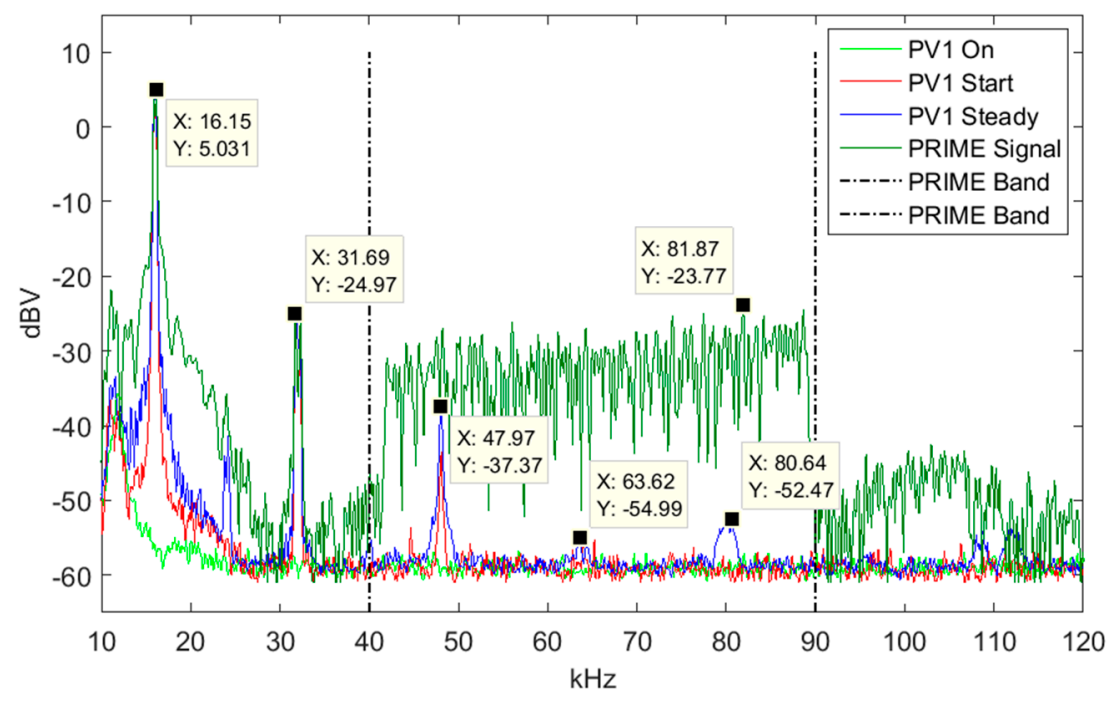

Figure 9. Spectrum recorded at the PV1 SM with the rest of devices disconnected.

\subsubsection{PV2}

The obtained spectra for the tests performed at the SM input of PV2 inverter can be seen in Figure 10, which shows a coloured pattern noise mainly composed by a set of supraharmonics with decreasing power levels, more noticeable in even supraharmonics. Both states, start and steady, present a similar spectral pattern with a slightly decrease of power levels (between 5 and $10 \mathrm{~dB}$ ) in even harmonic for steady operation. The main injection, located at $16 \mathrm{kHz}$ (equal to the switching frequency of the inverter) and $60 \mathrm{~dB}$ over the noise floor, is out of PRIME band, while its 3rd, 4th and 5 th harmonics are within the band of interest. The $3 \mathrm{rd}$ and the 5 th harmonics are $5 \mathrm{~dB}$ and $7 \mathrm{~dB}$ respectively above the recorded PRIME signal for the start phase, while during steady operation the power levels of these harmonics are similar to PRIME signal's power. In both cases, the 3rd harmonic is below the PRIME signal. Despite the existing power level of the noise, the associated SN remained connected and with stable coverage (values between 5 and 6 ) during all the performed tests. 


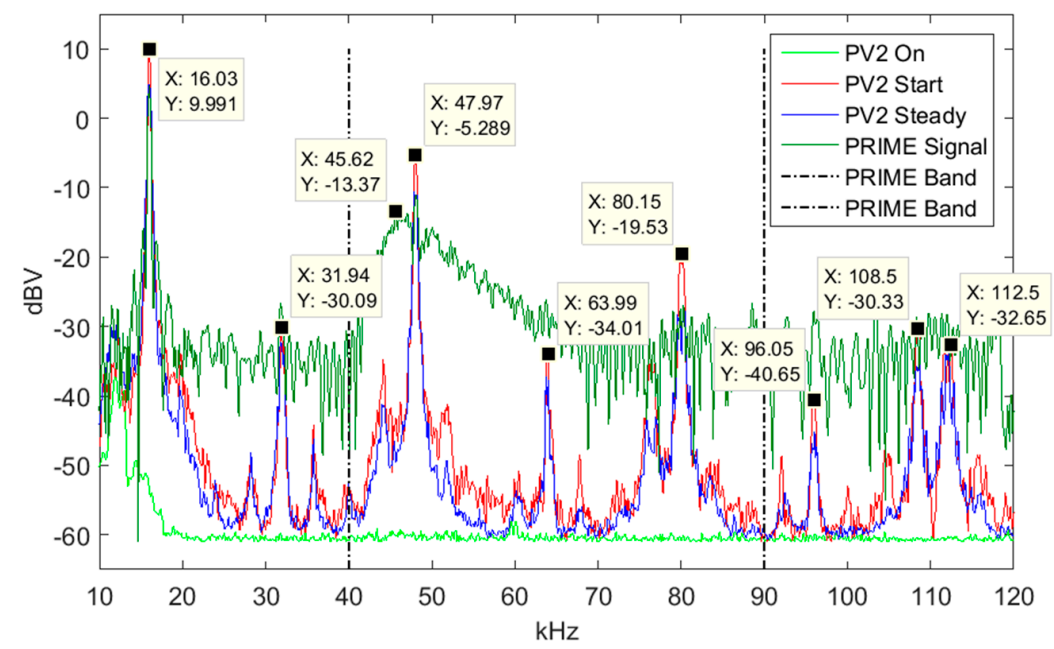

Figure 10. Spectrum recorded at the PV2 SM with the rest of devices disconnected.

\subsubsection{PV3}

The measurements performed at SM input of PV3 (see Figure 11) show a similar spectral pattern to the obtained for PV1 tests (Figure 9), with a main injection at $16 \mathrm{kHz}$ (equal to the switching frequency of PV3's inverter) which is $65 \mathrm{~dB}$ over the noise floor. As observed with PV1, both on and start operations present a similar spectrum pattern. The power level of the 3rd harmonic of the main injection, which is within PRIME band, reaches the same power level of the recorded PRIME signal $(38 \mathrm{dBV})$. The rest of the recorded emissions within the band of interest are clearly below the PRIME signal. The SN of PV3 remained connected during all the tests and its coverage was not affected, since values remained between 5 and 6 .

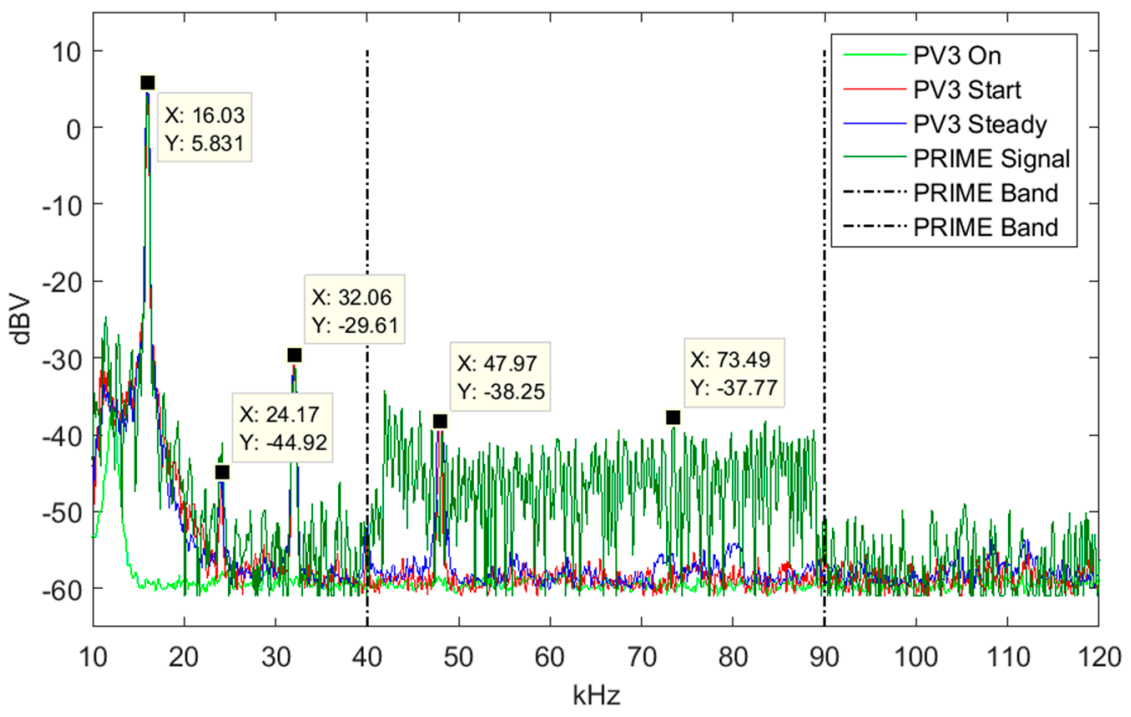

Figure 11. Spectrum recorded at the PV3 SM with the rest of devices disconnected.

\section{Influence of Distributed Energy Resources in Narrow-Band Power Line Communications}

This section analyses the influence of DER devices in PRIME communications by performing measurements under usual conditions in the microgrid (PV inverters switched on and battery charger, pump and turbine when required). The tests include the measurement of the spectrum and the analyses of the topological evolution and the coverage level of the SNs within the PRIME subnetwork through the $\log$ files. Additionally, the scenario of the battery charger is further analysed with the 
obtained MAC frames. Despite the subnetwork topology may change in any time under the BN criteria, a real recorded topology from the microgrid can be seen in Figure 12, where different states of the SNs (Figure 1), their unique MAC address and their coverage levels are shown. As observed in Figure 12, all the SNs located in the work cabin branch directly connect to the BN without needing any switch, while the SNs of the hydro system branch need several switching levels to reach the BN. Regarding disturbances, the decrease of coverage levels in a switch node will impact on its depending SNs. Therefore, the SNs located at the hydro branch are more susceptible to disconnection if any of their switches disconnects.

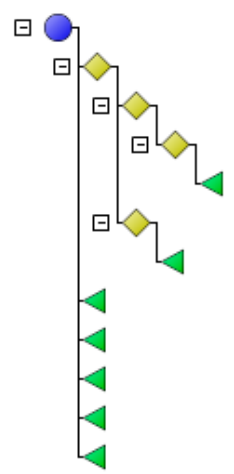

$\begin{array}{lll}\text { 40:40:22:01:d5:04 } & \text { Master DC } & \text { Base } \\ \text { 40:40:22:01:d5:09 } & \text { Slave DC } & \text { Switch } \\ \text { 40:40:22:59:55:6f } & \text { Hydro System } & \text { Switch } \\ \text { 40:40:22:59:55:74 } & \text { Turbine } & \text { Switch } \\ \text { 40:40:22:59:3a:14 } & \text { PV4 } & \text { Terminal } \\ \text { 40:40:22:59:55:7a } & \text { Capacitors } & \text { Switch } \\ \text { 40:40:22:59:3a:13 } & \text { Pump } & \text { Terminal } \\ \text { 40:40:22:48:6d:6d } & \text { PV1 } & \text { Terminal } \\ \text { 40:40:22:48:6d:6e } & \text { PV3 } & \text { Terminal } \\ \text { 40:40:22:48:6d:6f } & \text { Battery Charger } & \text { Terminal } \\ \text { 40:40:22:48:6d:74 } & \text { PV2 } & \text { Terminal } \\ \text { 40:40:22:59:55:87 } & \text { Work Cabin } & \text { Terminal }\end{array}$

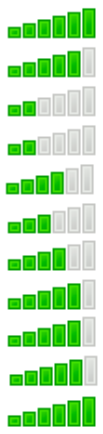

Figure 12. PRIME subnetwork topology obtained for the transformation centre under analysis in the microgrid at CEDER-CIEMAT facilities.

\subsection{Hydropower Turbine Smart Meter}

The spectra obtained for different states of the hydropower turbine with the surrounding devices switched on (in this case, PV4 and pump) can be seen in Figure 13. Additionally, a PRIME signal recorded during the tests is included. The primary injection at $12.95 \mathrm{kHz}$ during start state coincides with the recorded spectrum showed in Figure 4. Supraharmonics at around 18 and $27 \mathrm{kHz}$ also appear in Figure 4 but with slightly differences in power levels. However, Figure 13 shows a noticeable injection at $16 \mathrm{kHz}$ which appears also when the turbine is off but does not appear in Figure 4 . Then, its contribution must be caused by a surrounding device, which can be considered as a secondary emission. Regarding influence in the PRIME band, the power levels of the supraharmonics are significantly below the recorded PRIME signal. Finally, the coverage of the SN remained stable but the level decreased from 4-5 to 2, due to the influence of the surrounding DERs. However, the PRIME topology of the subnetwork remained stable and there were not switching promotion or disconnection of any node.

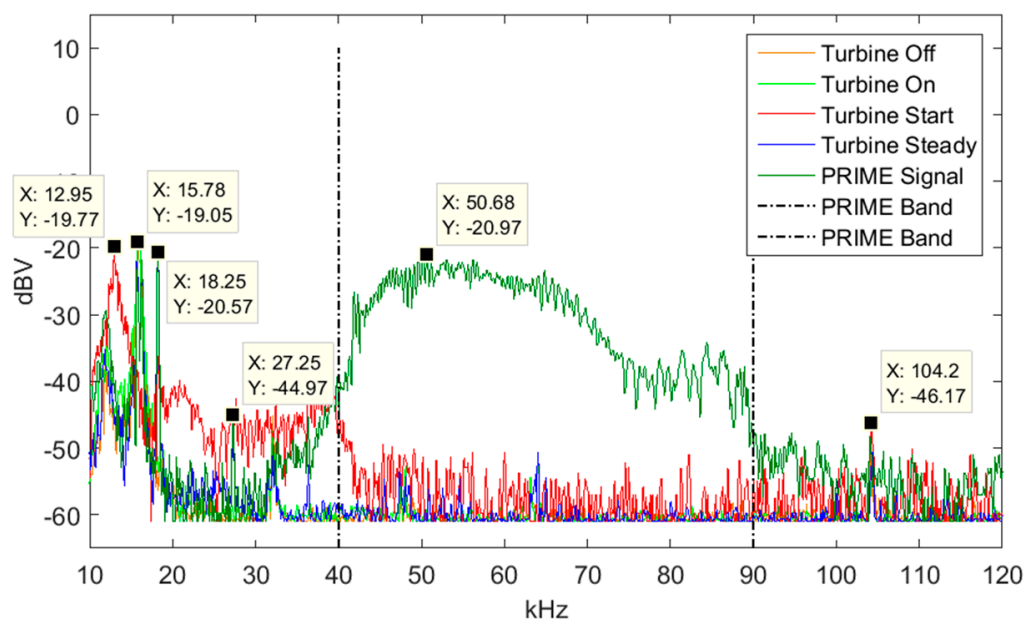

Figure 13. Spectrum recorded at the turbine SM with the rest of surrounding devices connected. 


\subsection{Hydropower Pump Smart Meter}

The obtained spectra at the hydropower pump SM after connecting the turbine and PV4 inverter can be seen in Figure 14. In contrast to the spectra obtained in Figure 6, Figure 14 shows noticeable injections at $16 \mathrm{kHz}$ and $18 \mathrm{kHz}$ of about $-14 \mathrm{dBV}$ and $-15 \mathrm{dBV}$ respectively, which are also present when the pump is off. Therefore, surrounding devices must be causing these disturbances, referred to as secondary emission. Observing Figures 4 and 13, this injection can be attributed to the hydropower turbine. Within PRIME band, the power levels are below the recorded PRIME signal. Only the start state generates interferences slightly above the PRIME signal level, but this transition is practically immediate and does not affect topology or SNs coverage. However, secondary emission affects the coverage and the topology. The coverage level of the pump SN decreased from 4 to 2 and even some level 1 were also observed. Regarding topology, the SN of the pump changed its switch. Since both the coverage levels of the pump SN and the one of its former switch "capacitor rack" decreased (see Figure 15) and attending to network maintenance and performance following the BN criterion, the pump SN established connection with turbine SN acting as switch.

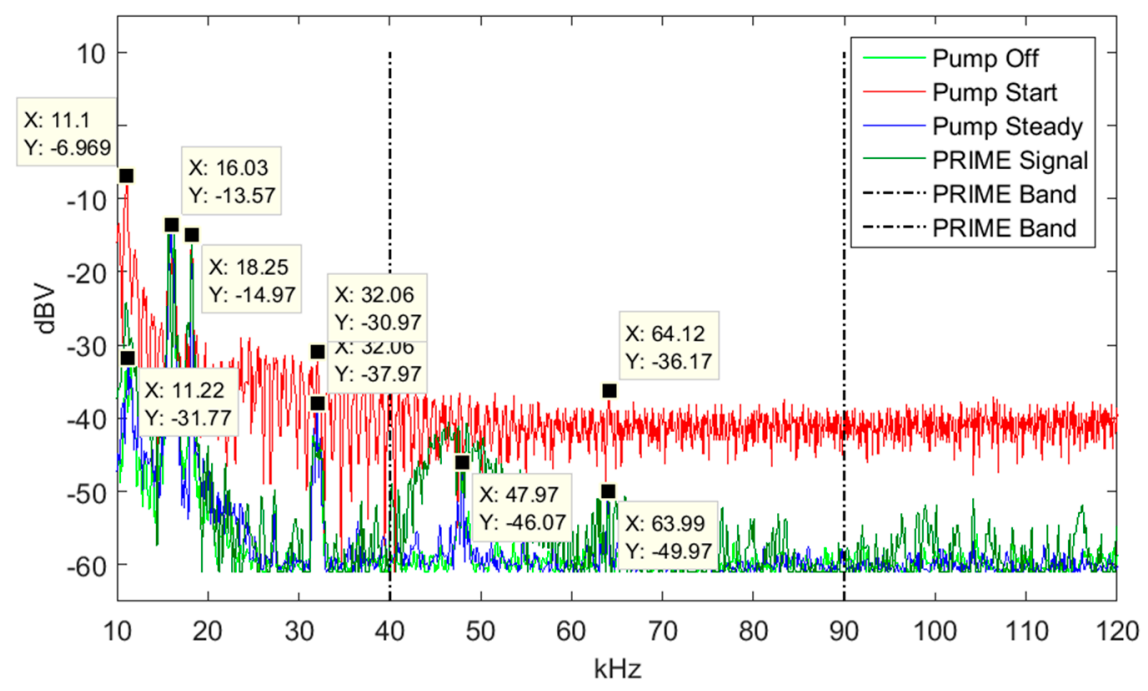

Figure 14. Spectrum recorded at the pump SM with the rest of surrounding devices connected.
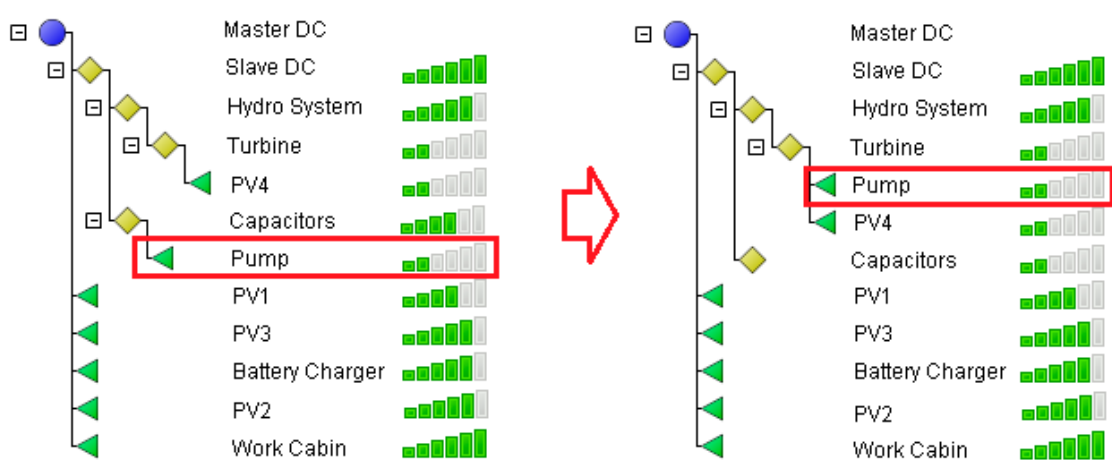

Figure 15. Change of switch for the pump SN when the pump is working and the rest of surrounding devices are connected.

\subsection{Three-Phased PV4 Inverter Smart Meter}

The spectra obtained for different states of the PV4 inverter with the hydropower turbine and the pump switched on and operating can be seen in Figure 16. The spectrum pattern is similar to the one obtained for the scenario shown in Figure 7 but the power levels of the main injection and the 
harmonics are slightly lower with the surrounding DER working (the maximum difference is $12 \mathrm{~dB}$ at $48 \mathrm{kHz}$ for start operation). Additionally, there is an extra injection at $18 \mathrm{kHz}$ which does not appear in Figure 7. As occurred with the pump scenario (Figure 14) and taking into account Figures 4 and 13, the injection at $18 \mathrm{kHz}$ can attributed to the hydropower turbine (secondary emission). Similarly, the PV4 inverter is the source of the injections at $16 \mathrm{kHz}$ shown in Figures 13 and 14 for the turbine and the pump, respectively, which do not appear when they operate isolated. Regarding PRIME communications, coverage fluctuations were observed (levels 1-3) for the PV4 SN during the test. However, the SN remained connected through the three switches (see Figure 12) at all times.

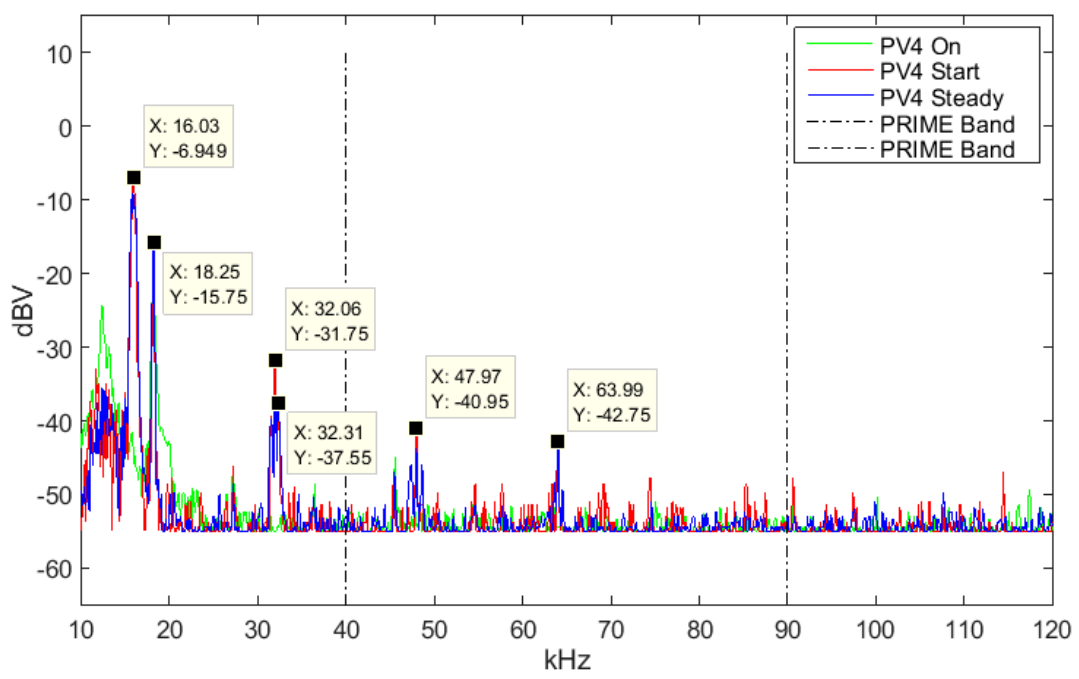

Figure 16. Spectrum recorded at the PV4 inverter SM with the rest of surrounding devices connected.

\subsection{Battery Charger Smart Meter}

As seen in the previous section, emissions from the battery charger highly affect PRIME communications. When it is charging the batteries, its associated SN disconnects from the PRIME subnetwork. Observing Figures 8 and 17, where emissions for different states of the charger can be seen, it can be concluded that surrounding devices also contribute to the spectral disturbances encountered at the SM input. A remarkable injection can be seen at $16 \mathrm{kHz}$ and cannot be attributed to the charger. Since PV1, PV3 and PV3 (Figures 9-11, respectively) present their main emission at $16 \mathrm{kHz}$, they must be contributing to the emissions obtained at the SM of PV3 inverter. The topological analysis shows that neither stand-by operation of the charger nor PV1, PV2 and PV3 inverters working and coupled to mains affected PRIME capabilities of the SN. The influence of the charger can be seen in Figure 18a,b), which show the evolution of the PRIME subnetwork configuration prior (stand-by) and after on operation of the charger, respectively. After the charger connection, both the SNs of the charger and PV3 are no longer able to communicate with the BN and disconnect from the subnetwork. As explained in the following subsection, PV1 promotes to switch since both PV3 and Charger SNs send requests so that their neighbour nodes can promote and then be able to establish a connection with the BN. However, PV3 and Charger SNs keep disconnected until the charger is switched off again. 


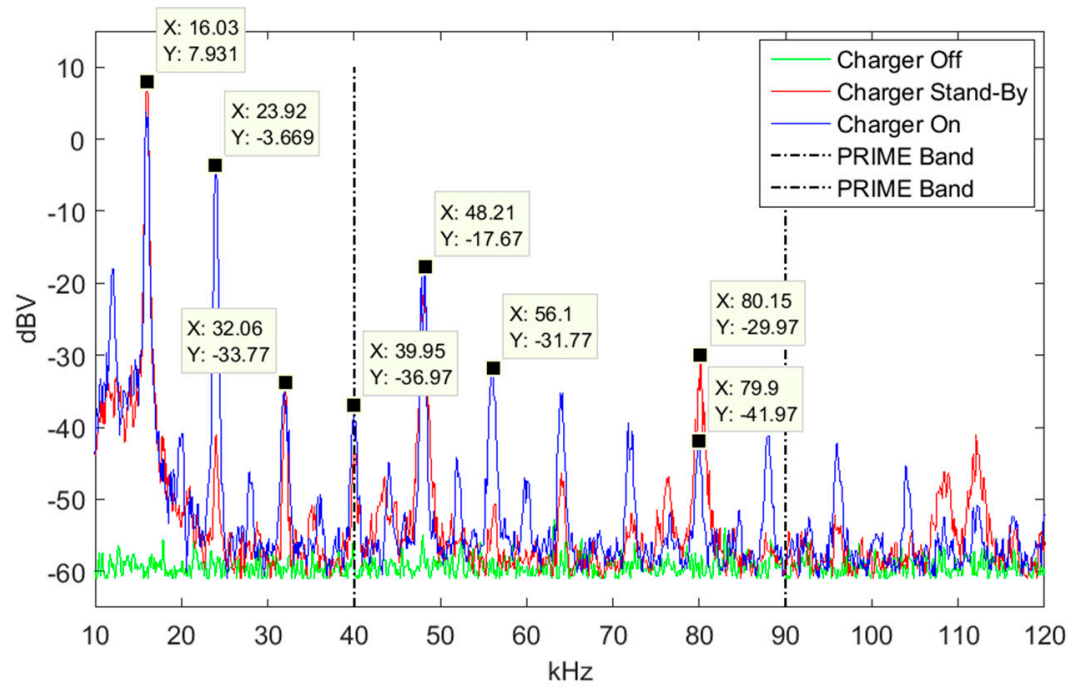

Figure 17. Spectrum recorded at the battery charger SM with the rest of surrounding devices connected.

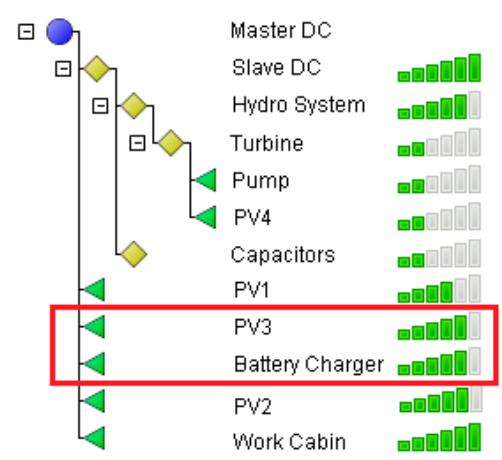

(a)

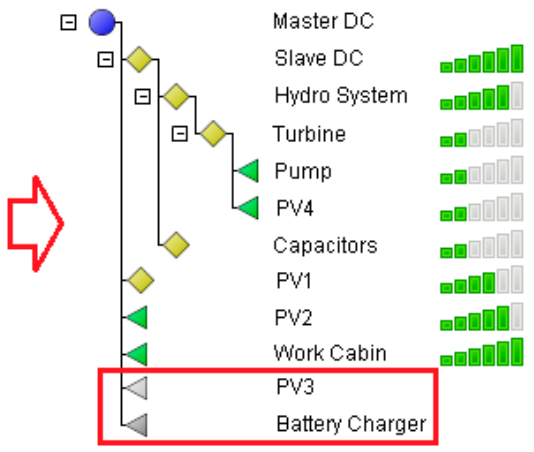

(b)

Figure 18. Evolution of PRIME subnetwork during (a) stand-by operation and (b) on operation of the battery charger. The states of PV3 and Charger SNs change to disconnected when the charger switches on.

\section{Medium Access Control Traffic Analysis}

MAC frames can be obtained in two ways: by recording the frames sent and received at the BN, and by connecting a MAC sniffer (PBN) at a desired point within the subnetwork. In both cases, a file containing the frames traffic is obtained. In this scenario, the PBN was connected at the charger SM (in the same electrical phase where PV3 is) and recorded a session in which the charger started in stand-by mode, after 10 minutes shifted to on for 21 hours and finally changed back to stand-by state. Therefore, two different logs are considered: the one recorded at the BN and another one from the PBN. Figure 19 shows some MAC traffic recorded during the session and Figure 20 shows the sequence of MAC packets between the BN and the PV3 SN and between the BN and the Charger SN, respectively. 


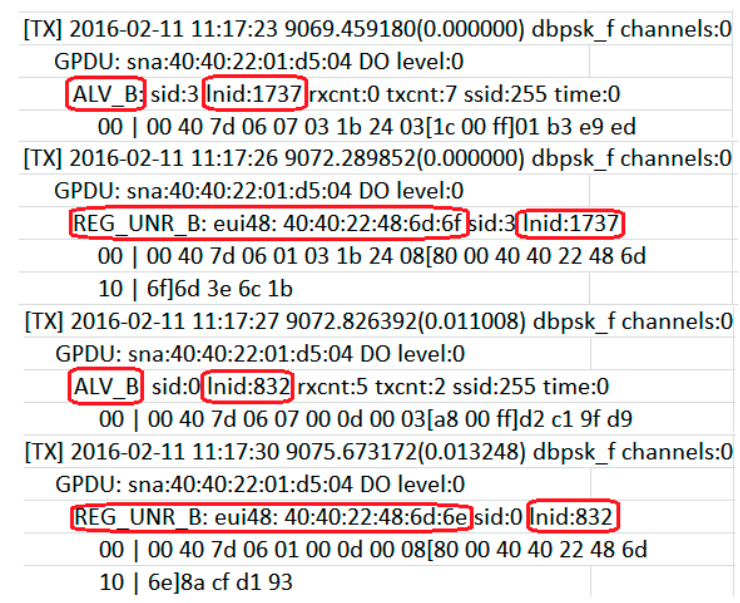

Figure 19. MAC traffic showing the last recorded Keep Alive messages and unregistration processes initiated by the BN for the SNs of the PV3 and the battery charger after the charger connection.

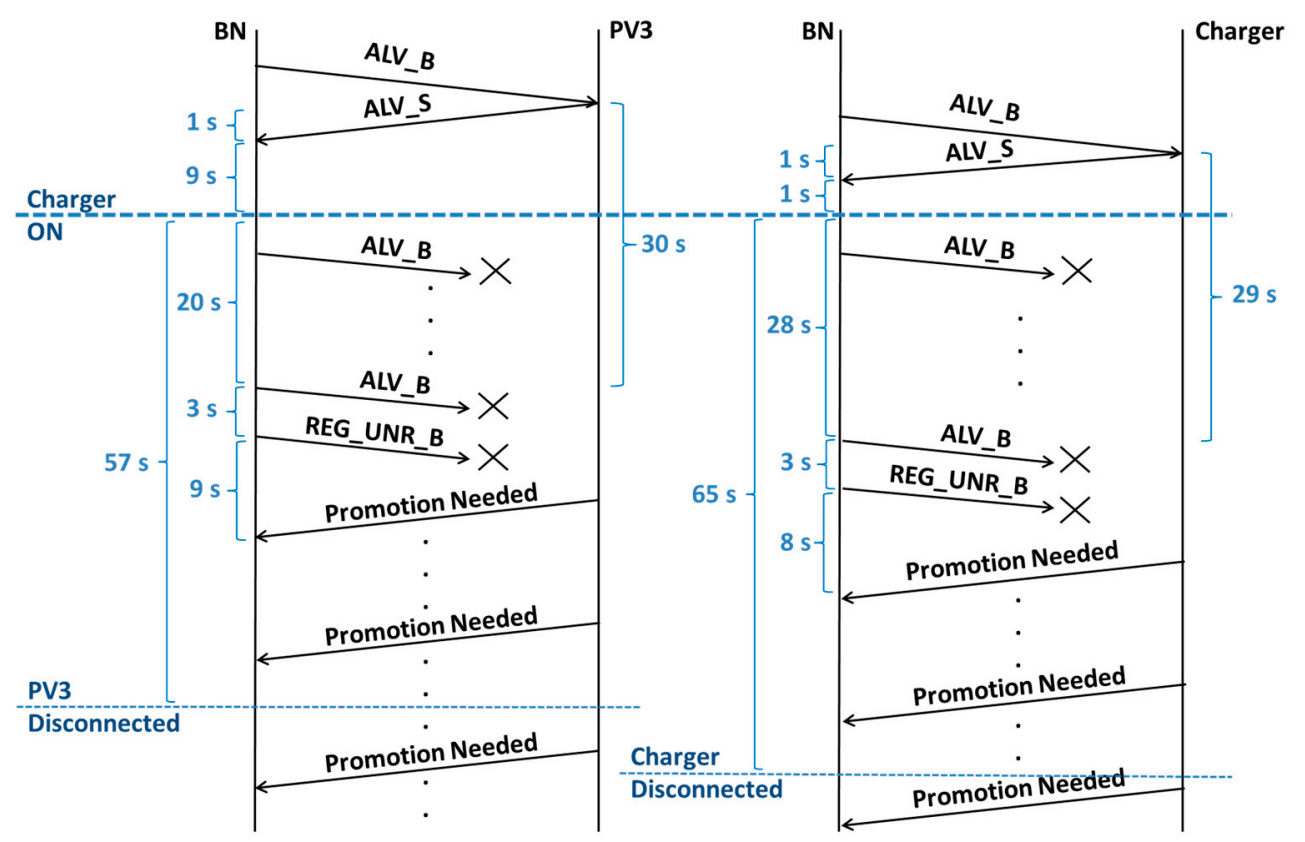

Figure 20. Sequence of MAC packets between the BN and the PV3 SN and between the BN and the Charger SN, respectively.

As part of the PRIME subnetwork management, the BN periodically sends Keep alive packets (ALV_B) to the SNs, to which SNs respond back with their own Keep alive packets (ALV_S). After the battery charger switches on, the BN keeps sending Keep alive packets to both the SNs of the charger (lnid: 1737) and the PV3 (lnid: 832). However, since the BN does not receive the Keep alive messages from the SNs, it starts the unregistration process (REG_UNR_B control packet) for both of them, as Figures 19 and 20 show. The BN waits 3 seconds between sending its last ALV_B and starting the unregistration for the SNs. Despite the sniffer, connected next to the charger SM, did not record any REG_UNR_B from the BN, the unregistration process started and both SNs appeared as disconnected 34 seconds after sending their corresponding REG_UNR_B. Considering the recorded spectra shown in Figures 8 and 17, communication may be interrupted due to the inability of Keep alive messages from the $\mathrm{BN}$ to reach the $\mathrm{SNs}$.

Two seconds before the REG_UNR_B packet was sent, the topology showed that the states of PV3 and Charger SNs changed to zombie (state prior to disconnection). Since the SNs stop receiving ALV_B 
from the BN (no ALV_B packets were registered by the sniffer located at the charger SM), as showed in Figure 20, they assume their disconnection from the subnetwork. However, they keep sending Promotion needed requests with the objective of being part of the subnetwork again. Disconnected nodes send Promotion needed requests to its neighbour nodes to indicate the need for the promotion of any available Terminal node. Concurring with the Promotion needed requests from the PV3 and the charger SNs, the SNs of the PV1, PV2 and work cabin, located under the same power transformer, changed their states to switch several times. However, neither the PV3 SN nor the Charger SN finally connected to the $\mathrm{BN}$ through any of them during the battery charger operation and remained disconnected until the charger was switched off again. In this case, despite the self-healing properties of the PRIME network, which tried to restore the communication with both the PV3 SN and Charger SN by means of modifications in the topology of the network, the unwanted emissions from the charger were disturbing enough to not make this possible during the charger operation.

\subsection{Single-Phased Photovoltaic Inverters}

\subsubsection{PV1}

Figure 21 shows the obtained spectra at the PV1 SM input with the rest of inverters operating and the charger disconnected. As occurred in Figure 9, the main injection at $16 \mathrm{kHz}$ and its harmonics are very noticeable and slightly stronger than when the inverter operates alone. The highest increase of power level occurs at $80 \mathrm{kHz}$, which is $12.7 \mathrm{~dB}$ above the same harmonic in Figure 9. The 3rd harmonic $(48 \mathrm{kHz})$, which is the strongest within the PRIME band, increases $5 \mathrm{~dB}$. These contributions are caused by the surrounding inverters, thus being secondary emission. Regarding the influence in the SN, it was stable and its coverage was not affected. Additionally, another set of measurements were performed for different states of the battery charger. As Figure 22 shows, there are some secondary emission (contribution at $24 \mathrm{kHz}$ ) from the battery charger, which is located in a different electrical phase than PV1's. Coverage level decreased (from level 5-6 to level 3) for the PV1 SN during charger operation, but it remained directly connected to the $\mathrm{BN}$ without the need of any switch.

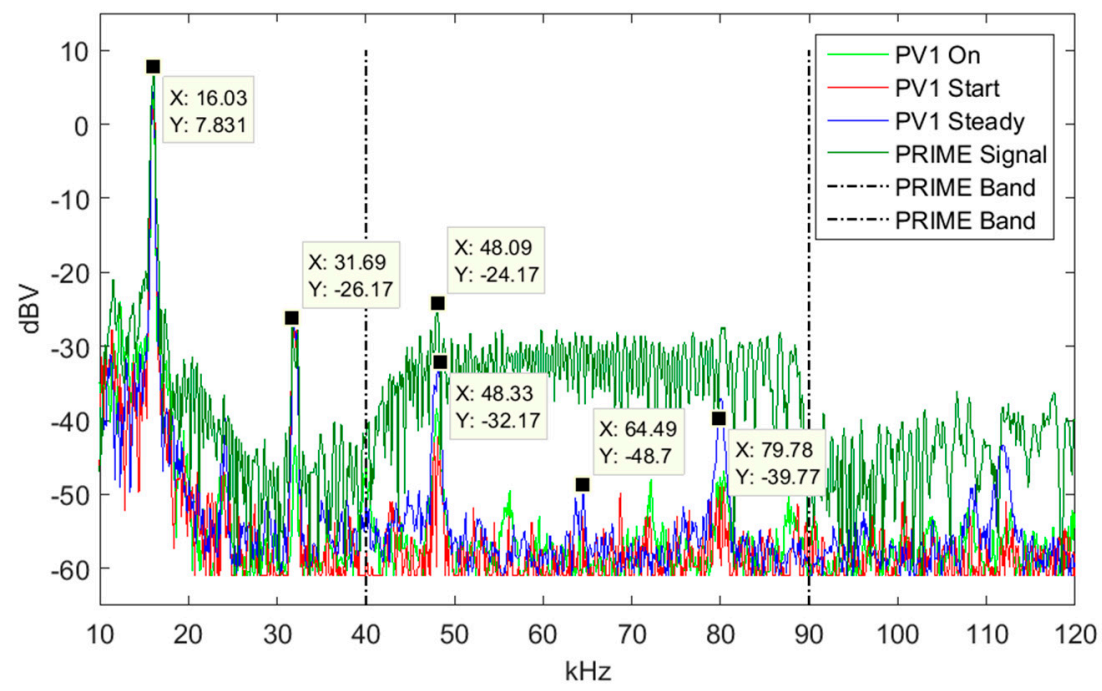

Figure 21. Spectrum recorded at PV1 inverter SM with the rest of inverters switched on and the battery charger disconnected. 


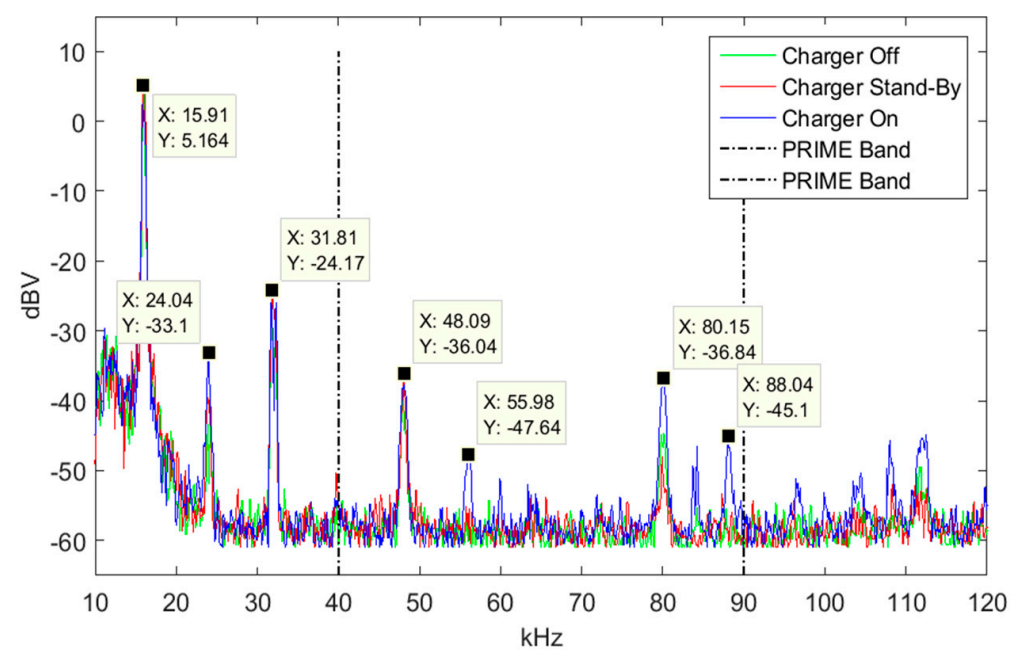

Figure 22. Spectrum recorded at PV1 SM for different states of the battery charger with the rest of inverters switched on.

\subsubsection{PV2}

The obtained spectrum at the PV2 SM input can be seen in Figure 23. As occurred in Figure 10, there is a slightly difference between the power levels of the start and the steady phases. The pattern of the spectrum is very similar in both scenarios and no remarkable contributions from surrounding devices can be identified in Figure 23, which also includes a registered PRIME signal. Despite the power level of the 3rd harmonic during the start state, which is inside PRIME band, is above the PRIME signal, the PV2 SN remained stable and its coverage was not affected.

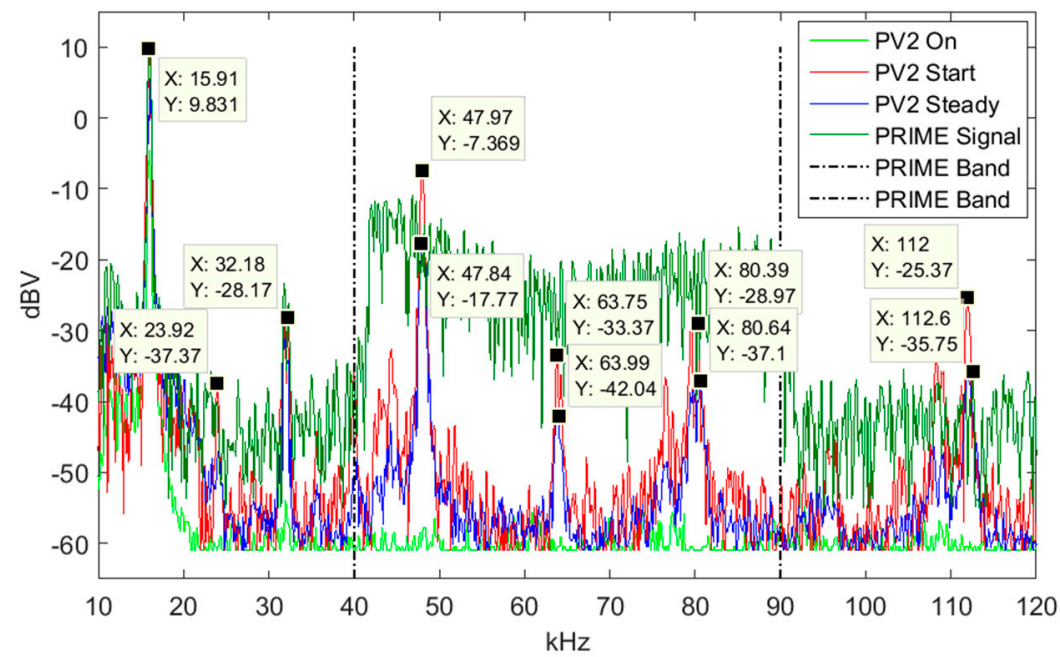

Figure 23. Spectrum recorded at PV2 inverter SM with the rest of inverters switched on and the battery charger disconnected.

As occurred with PV1, the spectrum recorded at PV2 SM with the charger switched on showed some significant secondary emission coming from the battery charger that affected the PV2 SN in terms of coverage (levels 2 and 3 were recorded) but the $\mathrm{SN}$ remained directly connected to the BN.

\subsubsection{PV3}

The SN of PV3 is highly affected by the battery charger, since they are located in the same electrical phase (see Figure 2). The emissions are harmful enough to disconnect not only the $\mathrm{SN}$ of the charger 
but also the SN of PV3 (see Figure 18). Figure 24 shows the recorded spectrum at PV3 SM with the three inverters working and coupled to mains and the charger disconnected. The harmonic at $48 \mathrm{kHz}$ increases $10 \mathrm{~dB}$ with regards to the emissions of the PV3 inverter alone (see Figure 11), which may suggest that PV1 and PV2 are contributing to the global emissions. Additionally, harmonics at $64 \mathrm{kHz}$ and $80 \mathrm{kHz}$, which do not appear in Figure 9, may come from PV2 (see Figure 10).

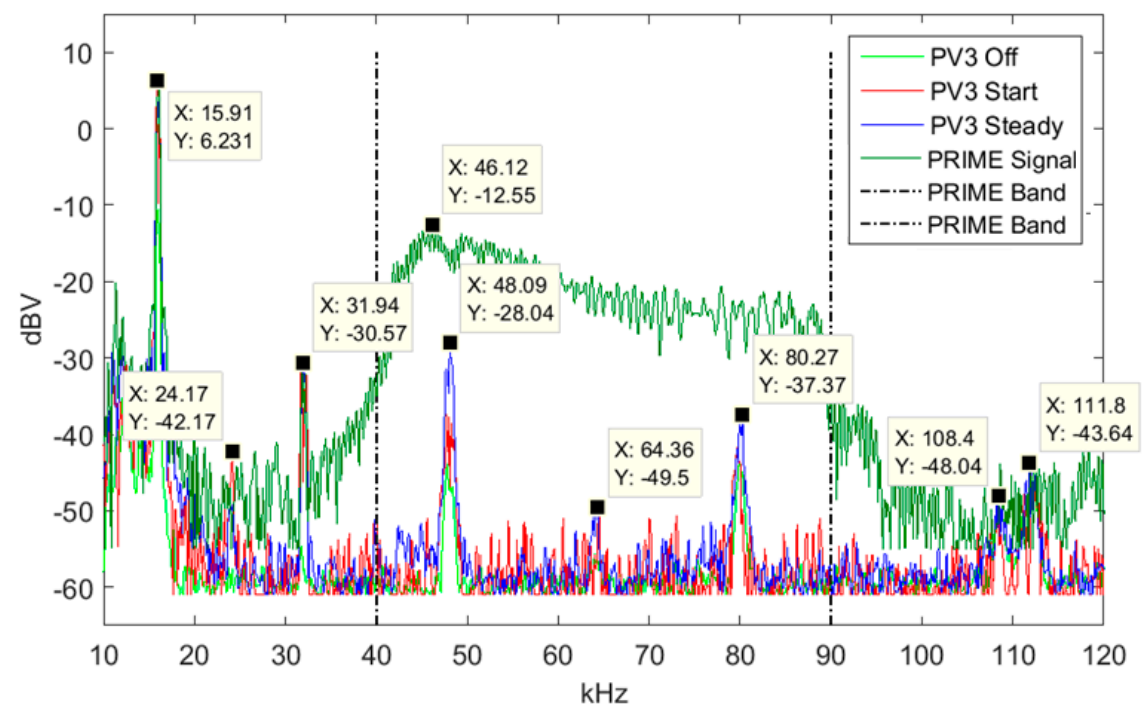

Figure 24. Spectrum recorded at PV3 inverter SM with the rest of inverters switched on and the battery charger disconnected.

Another set of measurements were performed with PV1, PV2 and PV3 connected and coupled to mains, for different states of the charger. Regarding recorded spectrum, Figure 25 clearly shows the contribution of the battery charger at $24 \mathrm{kHz}, 48 \mathrm{kHz}$ and $71 \mathrm{kHz}$ (see Figure 8), while the rest of harmonics remain similar to Figure 24. As expected, both the SNs of PV3 and the battery charger disconnect when the charger switches on. This test was repeated with PV1 and PV2 switched off and once again the SNs of PV3 and the battery charger disconnect when the charger switches on.

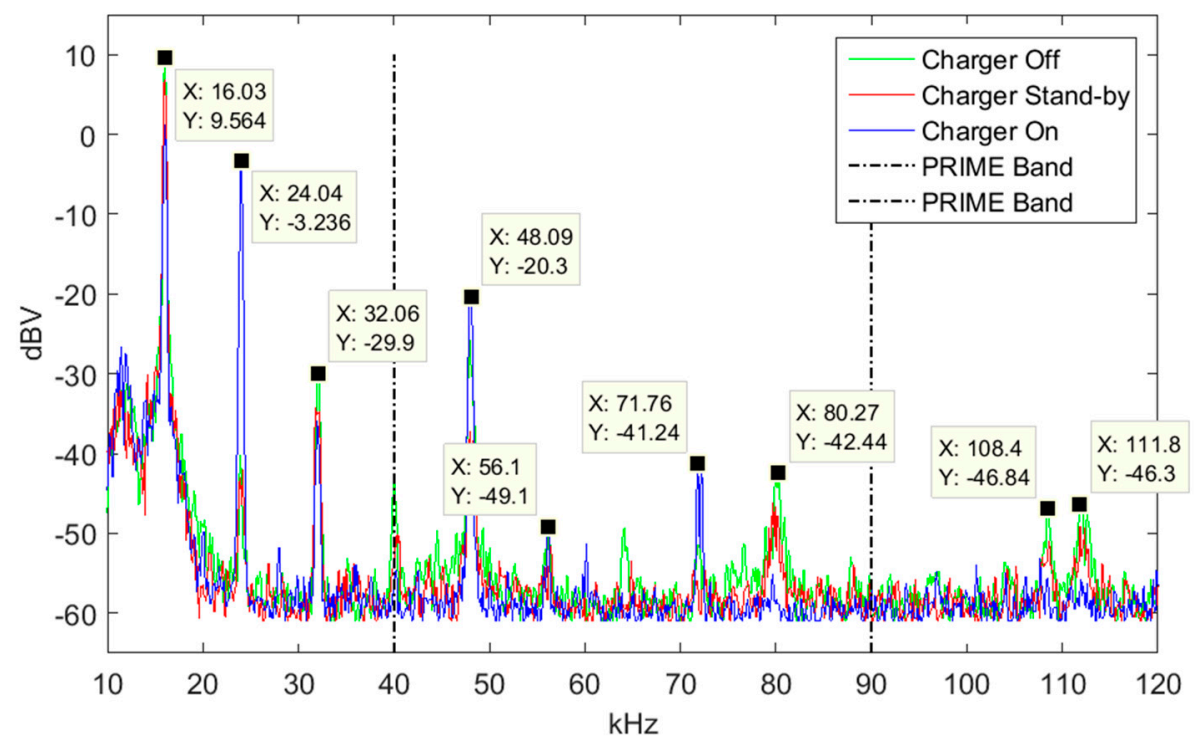

Figure 25. Spectrum recorded at PV3 SM for different states of the battery charger with the inverters switched on. 


\section{Discussion}

As presented in this work, disturbances from DER devices can affect NB-PLC communications. The research included in this paper is remarkable from two points of view. To begin with, the empirical spectra obtained through measurements from real devices fill the lack of them in existing literature (Section 5). This section also shows the influence of DERs over their corresponding SNs due to the presence of supraharmonics within the band of interest, as summarized in Table 3. Whereas in some cases the disturbances affect the level of coverage of the associated SN (Subsection 5.3-PV4) in other cases communications are fully cancelled (Subsection 5.4-Battery Charger).

Table 3. List of considered devices and summary of their influence over PRIME.

\begin{tabular}{|c|c|c|c|}
\hline \multirow{3}{*}{$\begin{array}{l}\text { Type of DER and } \\
\text { Main Features }\end{array}$} & \multicolumn{3}{|c|}{ Spectrum and Effect in PRIME (DER Standalone) } \\
\hline & \multirow{2}{*}{$\begin{array}{c}\text { Spectrum (10-120 kHz Range) } \\
\text { Main injection at } 13 \mathrm{kHz}\end{array}$} & \multicolumn{2}{|c|}{$\begin{array}{l}\text { SN Coverage Level } \\
\text { and Disconnection }\end{array}$} \\
\hline & & Stable (4-5) & No \\
\hline $\begin{array}{l}\text { Hydropower pump } \\
18 \mathrm{~kW} \text {, three-phased }\end{array}$ & Coloured noise with decreasing power level & Stable (4) & No \\
\hline $\begin{array}{l}\text { PV1 inverter } 5 \mathrm{~kW}, \\
\text { single-phased, } 16 \mathrm{kHz}\end{array}$ & $\begin{array}{l}\text { Main injection at switching frequency and } \\
\text { two remarkable harmonics }\end{array}$ & Stable (5-6) & No \\
\hline $\begin{array}{l}\text { PV2 inverter } 5 \mathrm{~kW} \text {, } \\
\text { single-phased, } 16 \mathrm{kHz}\end{array}$ & $\begin{array}{l}\text { Main injection at switching frequency and } \\
\text { four remarkable harmonics }\end{array}$ & Stable (5-6) & No \\
\hline $\begin{array}{l}\text { PV3 inverter } 5 \mathrm{~kW} \text {, } \\
\text { single-phased, } 16 \mathrm{kHz}\end{array}$ & $\begin{array}{l}\text { Main injection at switching frequency and } \\
\text { two remarkable harmonics }\end{array}$ & Stable (5-6) & No \\
\hline $\begin{array}{l}\text { PV4 inverter } 15 \mathrm{~kW} \text {, } \\
\text { three-phased, } 16 \mathrm{kHz}\end{array}$ & $\begin{array}{l}\text { Main injection at switching frequency and } \\
\text { two remarkable harmonics }\end{array}$ & Unstable (3-5) & No \\
\hline $\begin{array}{l}\text { Battery Charger } 8 \mathrm{~kW} \text {, } \\
\text { single-phased }\end{array}$ & $\begin{array}{l}\text { Main injection at } 24 \mathrm{kHz} \text { and two } \\
\text { remarkable harmonics }\end{array}$ & Highly affected & Yes \\
\hline
\end{tabular}

Secondly, the analysis of those emissions in a real microgrid (Section 6) demonstrates the importance of an analysis including not only spectrum results but also topological and coverage levels data due to the influence of emissions from different DERs among them. The performance of the study in a real working microgrid is valuable in three senses: firstly, because the increasing spread of microgrids worldwide is a fact; second, because PLC is one of the most employed technologies in microgrids and finally, because the considered microgrid includes several types of DERs rather than just PV systems. Focusing on PRIME, it has been shown that the performance of both MAC and PHY layers faced well most of the noisy scenarios. Taking into account the aforementioned, several aspects of noise effect in communications can be identified:

- Influence of secondary emissions: the coverage level of a SN may be affected not only by its associated DER but also by surrounding emitting devices, referred to as secondary emission, as seen in the hydro-system branch. The combination of all the emitting devices affected the coverage levels of most of the SNs within the same electrical branch.

- Subnetwork topology reconfiguration: in some cases, the disturbances are faced by changes in topology, as showed in Subsection 6.2-Hydro Pump. The switch of Pump SN, whose coverage decreased due to the influence of surrounding DERs, changed to a more robust $\mathrm{SN}$ acting as switch. In the worst case, an emitting DER can affect the SN of a neighbour device to the point of cancelling its communications (Subsection 6.4-Battery Charger). As explained in the MAC analysis and despite all the Promotion needed requests from both the PV3 and Charger SNs, there were not changes in topology able to reconnect them to the subnetwork while the charger was working. Therefore, SNs remained inaccessible until the charger was switched off again. 
- Propagation of the emissions: the influence of a single-phased DER, such as the battery charger, might also affect the coverage level of the SNs located in different electrical phases, as seen in Subsection 6.5-PV Inverters. The coverage levels of both PV1's and PV2's SNs decreased during charger's operation, but that was not the case during isolated performance of the PV inverters.

Addressing those issues would not have been possible with just a spectral study from an isolated resource. Additionally, the included MAC analysis for the case of the battery charger helps to better understand the sequence of disconnections through the messages exchange between the $\mathrm{BN}$ and the SNs.

In view of the above, further considerations can be drawn:

- Despite an emission may not be harmful enough to block the access to a SN, it can cause changes in the topology that can isolate existing SNs. Additionally, if the blocked SN was acting as a switch, all its dependent SNs may result inaccessible as well. This is especially crucial in microgrids with a large number of DERs, regardless of their extent, since the joint action of all the emissions might block SNs.

- The influence of noise in communications goes beyond changes in topology or SN's coverage level and accessibility, since it also affects data traffic. Firstly, disturbances can affect data packets by corrupting or cancelling them. In either case, a retransmission will be required. Secondly, the increase of data traffic (either due to changes in topology, retransmissions or both) affect the overall performance of the subnetwork since the available bandwidth is reduced. A direct consequence of the higher data traffic is the increase of the packets collision, which in turn translates into more lost data and packet retransmissions. If non-crucial data is lost, its retransmission may solve the inconvenience. In the worst case, lost data may lead to microgrid instability if control packets are affected. In these scenarios, the self-healing capabilities of the communication network will play a key role since they must be designed to overcome those problems.

- Major functionalities of microgrids such as monitoring and controlling implement a communication system. Consequently, the disturbances affecting communications may also affect them. For instance, controlling actions over a specific SN may not be possible if it is inaccessible due to surrounding emissions. This fact highlights the importance of addressing noise disturbances in microgrids.

\section{Conclusions}

As an overall conclusion, the work presented here demonstrates that emissions from DER can affect PLC communications and that the study of the influence of noise entails a complex analysis, highly dependent on the particular subnetwork topology of a microgrid. Additionally, since there are no standard limits to compare with it is difficult to classify emissions in this frequency range as high, medium or low [17]. In this regard, the presented work contributes to fulfill the need for measures to ensure Electromagnetic Compatibility EMC in the frequency range 2-150 kHz. Regarding NB-PLC, a solution which ensures co-existence between Non-Mains Communicating Equipment and Mains Communicating Systems is needed. If the problem is still being addressed, so are solutions. Currently discussions in standardization committees like IEC SC 77A WG8 on this topic divide into strives for standardized emission limitation and immunity requirements; and into agreement upon less stringent emission limits and immunity requirements. Then, two different approaches emerge regarding the possible solutions: on one hand, those ones focused on strictly limiting the emission of electrical equipment whether they are within a PLC context or not. Therefore, the increase in production costs of the devices will be borne by manufacturers. On the other hand, the second approach advocates for smoothing emitting restrictions and solve each emerging issue case-by-case, leaving unclear who bears the costs. The different implied agents with different positions and interests also contribute to polarize the discussion [5].

For all the aforementioned, this work constitutes an important contribution to existing efforts towards the recommendations and standardization of emissions in the range from 2 to $150 \mathrm{kHz}$. 
The work can also be helpful in future microgrids and smart metering systems deployments and serve as guidelines for the improvement of both PLC and DER devices.

Acknowledgments: This work has been partially supported by Microgrids with Renewable Distributed Generation (MIGEDIR) (project 713RT0468), funded by the Science and Technology for Development Iberoamerican Program (CYTED). The authors would like to thank Raúl Gómez and Siro Soria for their help in the measurement setup; and ZIV for providing the smart metering equipment as well as for giving their support for the measurements.

Author Contributions: All authors have coordinately worked in the different parts of the document.

Conflicts of Interest: The authors declare no conflict of interest.

\section{References}

1. Laverty, D.M.; Morrow, D.J.; Best, D.J.; Crossley, P.A. Telecommunications for smart grid: Backhaul solutions for the distribution network. In Proceedings of the Power and Energy Society General Meeting, Minneapolis, MN, USA, 25-29 July 2010; pp. 1-6.

2. Uribe-Pérez, N.; Hernández, L.; de la Vega, D.; Angulo, I. State of the Art and Trends Review of Smart Metering in Electricity Grids. Appl. Sci. 2016, 6. [CrossRef]

3. Yoon, S.; Jang, S.; Kim, Y.; Bahk, S. Opportunistic Routing for Smart Grid With Power Line Communication Access Networks. IEEE Trans. Smart Grids 2014, 5, 303-311. [CrossRef]

4. Bollen, M.H.J.; Rönnberg, S.; Zavoda, F. CIGRE/CIRED C4.24-Power quality in the future grid-First introduction. In Proceedings of the Great Lakes Symposium on Smart Grids, Chicago, IL, USA, 22-25 September 2014.

5. CENELEC. CLC/SC205A Study Report on Electromagnetic Interference between Electrical Equipment/Systems in the Frequency Range below 150 kHz, Edition 3. Available online: http:/ /www.kigeit.org.pl/FTP/bu/grse/ repozytorium/tc210_sec0898_inf_(clc-sc205a_study_report_ed3).pdf (accessed on 25 November 2016).

6. Galli, S.; Scaglione, A.; Wang, Z. For the grid and through the grid: The role of power line communications in the smart grid. Proc. IEEE 2011, 99, 998-1027. [CrossRef]

7. Rönnberg, S.; Bollen, M.H.J. Measurements of primary and secondary emission in the supraharmonic frequency range 2-150 kHz. In Proceedings of the CIRED 23rd International Conference and Exhibition on Electricity Distribution, Lyon, France, 15-18 June 2015.

8. Moreno-Muñoz, A.; Gil-de-Castro, A.; Rönnberg, S.; Bollen, M.; Romero-Cadaval, E. Ongoing work in CIGRE working groups on supraharmonics from power-electronic converters. In Proceedings of the CIRED 23rd International Conference and Exhibition on Electricity Distribution, Lyon, France, 15-18 June 2015.

9. Larsson, E.O.A.; Bollen, M.H.J.; Wahlberg, M.G.; Lundmark, M.G.; Ronnberg, S.K. Measurements of high-frequency (2-150 kHz) distortion in low-voltage networks. IEEE Trans. Power Deliv. 2010, 25, 1749-1757. [CrossRef]

10. Varatharajan, A.; Schoettke, S.; Meyer, J.; Abart, A. Harmonic emission of large PV installations case study of a $1 \mathrm{MW}$ solar campus. In Proceedings of the ICREPQ International Conference on Renewable Energies and Power Quality, Cordoba, Spain, 8-10 April 2014.

11. Rönnberg, S.; Wahlberg, M.; Larsson, A.; Bollen, M.; Lundmark, M. Interaction between equipment and power line communication: 9-95 kHz. In Proceedings of the 2009 IEEE Bucharest PowerTech, Bucharest, Romania, 28 June-2 July 2009.

12. Leroi, C.; De Jaeger, E. Conducted disturbances in the frequency range $2-150 \mathrm{KHz}$ : Influence of the LV distribution grids. In Proceedings of the CIRED 23rd International Conference and Exhibition on Electricity Distribution, Lyon, France, 15-18 June 2015.

13. Knockaert, J. High Frequency Power Quality. CE-ABLE Seminar. Ghent University, 2016. Available online: http:/ / www.emcseminar.eu/sites/default/files/uploads/09.45\%20HFPQ $\% 202 \% 20 \% \mathrm{E} 2 \% 80 \% 93 \% 20150 \%$ $20 \mathrm{kHz}, \% 20 \mathrm{free} \% 20 \mathrm{of} \% 20$ standards, $\% 20 \mathrm{but} \% 20$ not $\% 20$ free $\% 20$ of $\% 20$ troubles $\% 20$ Jos $\% 20$ Knockaert.pdf (accessed on 11 July 2016).

14. Rönnberg, S.; Bollen, M.; Gil-de-Castro, A. Harmonic Distortion from Energy-Efficient Equipment and Production in the Low-Voltage Network; Research Report; Luleå University of Technology: Luleå, Sweden, 2014.

15. Rönnberg, S. Emission and Interaction from Domestic Installations in the Low Voltage Electricity Network up to $150 \mathrm{kHz}$. Ph.D. Thesis, Luleå University of Technology, Luleå, Sweden, 2013. 
16. Rönnberg, S.; Bollen, M.H.J. Emission from four types of LED lamps for frequencies up to $150 \mathrm{kHz}$. In Proceedings of the 2012 IEEE 15th International Conference on Harmonics and Quality of Power (ICHQP), Hong Kong, China, 17-20 June 2012; pp. 451-456.

17. Rönnberg, S.; Bollen, M.; Larsson, A. Grid impact from PV-installations in northern Scandinavia. In Proceedings of the CIRED 22nd International Conference on Electricity Distribution, Stockholm, Sweden, 10-13 June 2013.

18. Rönnberg, S. Power Line Communication and Customer Equipment. Licentiate Thesis, Luleå University of Technology, Luleå, Sweden, 2011.

19. Nejadpak, A.; Sarikhani, A.; Mohammed, O.A. Analysis of radiated EMI and noise propagation in three-phase inverter system operating under different switching patterns. IEEE Trans. Magn. 2013, 49, 5, 2213-2216. [CrossRef]

20. Rönnberg, S.; Bollen, M.; Larsson, A. Emission from small scale PV-installations on the low voltage grid. In Proceedings of the International Conference on Renewable Energy and Power Quality (ICREP'14), Córdoba, Spain, 8-10 April 2014.

21. Meyer, J.; Bollen, M.; Amaris, H.; Blanco, A.M.; de Castro, A.G.; Desmet, J.; Yang, K. Future work on harmonics-some expert opinions Part II-supraharmonics, standards and measurements. In Proceedings of the 16th International Conference on Harmonics and Quality of Power (ICHQP), Bucharest, Romania, 25-28 May 2014; pp. 909-913.

22. Lindberg, E.; Anette, A.; Urban, A. Power Quality Analysis of a $110 \mathrm{MW}$ Wind Farm in a $130 \mathrm{kV}$ Switchyard. Elforsk Report. 2012. Available online: http://www.elforsk.se/Global/Vindforsk/Rapporter\%20VFIII/13_ 13_report.pdf (accessed on 2 July 2016).

23. Schöttke, S.; Meyer, J.; Schegner, P.; Bachmann, S. Emission in the frequency range of $2 \mathrm{kHz}$ to $150 \mathrm{kHz}$ caused by electrical vehicle charging. In Proceedings of the International Symposium on Electromagnetoic Compatibility (EMC Europe), Gothenburg, Sweden, 1-4 September 2014.

24. Kotsampopoulos, P.; Rigas, A.; Kirchhof, J.; Messinis, G.; Dimeas, A.; Hatziargyriou, N.; Rogakos, V.; Andreadis, K. EMC issues in the interaction between smart meters and power electronic interfaces. IEEE Trans. Power Deliv. 2016, 99, 1. [CrossRef]

25. Klatt, M.; Meyer, J.; Schegner, P.; Koch, A.; Myrzik, J.; Körner, C.; Darda, T.; Eberl, G. Emission Levels above $2 \mathrm{kHz}$. Laboratory results and survey measurements in public low voltage grids. In Proceedings of the CIRED 22nd International Conference on Electricity Distribution, Stockholm, Sweden, 10-13 June 2013.

26. Klatt, M.; Meyer, J.; Schegner, P.; Wolf, R.; Wittenberg, B. Filter for the measurement of supraharmonics in public low voltage networks. In Proceedings of the EMC 2015 IEEE International Symposium on Electromagnetic Compatibility, Dresden, Germany, 16-22 August 2015.

27. Bartak, G.F.; Abart, A. EMI of emissions in the frequency range $2 \mathrm{kHz}-150 \mathrm{kHz}$. In Proceedings of the CIRED 22nd International Conference on Electricity Distribution, Stockholm, Sweden, 10-13 June 2013.

28. Rönnberg, S.; Wahlberg, M.; Bollen, M.; Larsson, A.; Lundmark, C. Measurements of interaction between equipment in the frequency range 9 to $95 \mathrm{kHz}$. In Proceedings of the CIRED 18th International Conference on Electricity Distribution, Prague, Czech Republic, 8-11 June 2009.

29. Rönnberg, S.; Bollen, M.H.J.; Wahlberg, M. Interaction between narrowband power-line communication and End-User equipment. IEEE Trans. Power Deliv. 2011, 26, 2034-2039. [CrossRef]

30. Bashi, S.M. Effects of high power electronics converters on PLC signals. J. Appl. Sci. 2006, 6, 1888-1891.

31. Pikkarainen, M.; Vehmasvaara, S.; Siddiqui, B.A.; Pakonen, P.; Verho, P. Interference of touch dimmer lamps due to PLC and other high frequency signals. In Proceedings of the Electric Power Quality and Supply Reliability Conference (PQ), Tartu, Estonia, 11-13 June 2012; pp. 1-6.

32. Götz, M.; Rapp, M.; Dostert, K. Power line channel characteristics and their effect on communication system design. IEEE Commun. Mag. 2004, 42, 78-86. [CrossRef]

33. Guibout, J.G.; García Garino, C.; Fusario, R.J.; Castro-Lechtaler, A.R.; Sevilla, G. Comportamiento de la Tecnología PLC en la Red Eléctrica. In Proceedings of the XIII Congreso Argentino de Ciencias de la Computación, Corrientes, Argentina, 1-5 October 2007.

34. Szén, I.; Rácz, E. Use of the Power Line Communication System (PLC) at low voltage $(0.4$ kV) noisy electrical networks-Introducing a new concept at power quality. In Proceedings of the International Conference on Renewable Energies and Power Quality (ICREPQ), Santiago de Compostela, Spain, 28-30 March 2012. 
35. Guezgouz, D.; Chariag, D.E.; Raingeaud, Y.; Le Bunetel, J.C. Modeling of electromagnetic interference and PLC transmission for loads shedding in a microgrid. IEEE Trans. Power Electron. 2011, 26, 747-754. [CrossRef]

36. Patel, S.N.; Robertson, T.; Kientz, J.A.; Reynolds, M.S.; Abowd, G.D. At the flick of a switch: Detecting and classifying unique electrical events on the residential power line. In Proceedings of the International Conference on Ubiquitous Computing, Innsbruck, Austria, 16-19 September 2007; pp. 271-288.

37. Barmada, S.; Raugi, M.; Rizzo, R.; Tucci, M. Channel evaluation for power line communication in plug-in electric vehicles. IET Electr. Syst. Transp. 2012, 2, 195-201. [CrossRef]

38. Panchadcharam, S.; Taylor, G.A.; Pisica, I.; Irving, M.R. Modeling and analysis of noise in power line communication for smart metering. In Proceedings of the 2012 IEEE Power and Energy Society General Meeting, San Diego, CA, USA, 22-26 July 2012; pp. 1-8.

39. Korki, M.; Zhang, C.; Vu, H.L. Performance evaluation of PRIME in smart grid. In Proceedings of the IEEE International Conference on Smart Grid Communications (SmartGridComm), Vancouver, BC, Canada, 21-24 October 2013; pp. 21-24, 294-299.

40. PRIME Alliance. Draft Standard for Powerline Intelligent Metering Evolution, Version R.1.3.6. Available online: http://www.prime-alliance.org/wp-content/uploads/2013/04/PRIME-Spec_v1.3.6.pdf (accessed on 12 April 2016).

41. Uribe-Pérez, N.; Hernández, L.; Gómez, R.; Soria, S.; de la Vega, D.; Angulo, I.; Arzuaga, T.; Gutiérrez, L. Smart management of a distributed generation microgrid through PLC PRIME technology. In Proceedings of the 2015 International Symposium on Smart Electric Distribution Systems and Technologies (EDST), Vienna, Austria, 8-11 September 2015; pp. 374-379.

(C) 2016 by the authors; licensee MDPI, Basel, Switzerland. This article is an open access article distributed under the terms and conditions of the Creative Commons Attribution (CC-BY) license (http:/ / creativecommons.org/licenses/by/4.0/). 